\title{
The mechanistic investigation on hydrogen donation performance of bio-acids over bi- functional carbon nanotube catalysts
}

Jiajun Zhang

University of Strathclyde

Xiaolei Zhang ( $\nabla$ xiaolei.zhang@strath.ac.uk)

University of Strathclyde https://orcid.org/0000-0001-9415-3136

Dekui Shen

Southeast University

\section{Research}

Keywords: Acetic acid, carbon nano tubes (CNTs), hydrogen donor, catalytic upgrading, biofuels

Posted Date: March 24th, 2020

DOI: https://doi.org/10.21203/rs.3.rs-18837/v1

License: (c) (1) This work is licensed under a Creative Commons Attribution 4.0 International License.

Read Full License 


\section{Abstract}

\section{Background}

Bio-acids such as acetic acid ( $\mathrm{AcOH}$ ) and formic acid (FA) are typical bio-oil compounds and platform chemicals that sourced from biomass pyrolysis. They are attracting global research attention due to their low-cost and safety merits with additional potentials as alternative in-situ hydrogen donors for bio-oil upgrading. However, the hydrogen donation performance of bio-acids have not been sufficiently evaluated, especially, investigation on high efficient catalysts to promote the process is lacking. In this study, novel catalysts of metal supported on nitrogen doped carbon nanotubes (CNTs) were thoroughly evaluated in facilitating the decomposition of both $\mathrm{FA}$ and $\mathrm{AcOH}$ for hydrogen donation by comparing ten different metal loadings and six types of CNT based substrates.

Results

It was found that Mo loading enabled the strongest binding energy to the bio-acid molecule among the ten evaluated transition metals, and Np (pyridinic nitrogen doped)-CNT led to bigger adsorption energy of $\mathrm{AcOH}$ than other substrates, e.g. $\mathrm{Ng}$ (graphitic nitrogen doped)-CNT or non-doped CNT. The new designed catalyst, Mo/N-CNTs, considerably facilitated the bio-acids decomposition by lowering the energy barriers, compared to the non-catalytic scenario. The favourable hydrogen donation pathways for $\mathrm{AcOH}$ are: $\mathrm{CH} 3 \mathrm{COOH} \rightarrow \mathrm{CH} 3 \mathrm{CO} \rightarrow \mathrm{CH} 3 \rightarrow \mathrm{CH} 2 \rightarrow \mathrm{CH} \rightarrow \mathrm{C}$ over $\mathrm{Mo} / \mathrm{Np}-\mathrm{CNT}$, and $\mathrm{CH} 3 \mathrm{COOH} \rightarrow \mathrm{CH} 3 \mathrm{CO} \rightarrow \mathrm{CH} 3 \mathrm{C} \rightarrow \mathrm{CH} 3 \rightarrow \mathrm{CH} 2 \rightarrow \mathrm{CH} 1 \rightarrow \mathrm{C}$ over Mo/Ng-CNT. The pathways for FA are: $\mathrm{HCOOH} \rightarrow \mathrm{H}+\mathrm{CO}+\mathrm{OH}$ over $\mathrm{Mo} / \mathrm{Np}-\mathrm{CNT}$ and $\mathrm{HCOOH} \rightarrow \mathrm{HCO}+\mathrm{OH}$ over $\mathrm{Mo} / \mathrm{Ng}-\mathrm{CNT}$. FA has showed the superiority for hydrogen donation than $\mathrm{AcOH}$ over Mo/N-CNT catalysts since it can be cleaved into hydroxyl group and hydrogen without an energy barrier, which will facilitate the following hydrogen donation from hydroxyl.

\section{Conclusions}

It was concluded that the new explored catalyst, Mo/N-CNTs, significantly lowered the decomposition energy barriers for both $\mathrm{AcOH}$ and $\mathrm{FA}$ thus promoting the hydrogen donation performance of both bioacids. Additionally, over the designed catalyst, $\mathrm{FA}$ is a preferred hydrogen donor than $\mathrm{AcOH}$ due to the barrier-free adsorption step while the energy barriers for $\mathrm{AcOH}$ decompositions are relatively high.

\section{Background}

Bioenergy utilisation is a long-term worldwide strategy to reduce $\mathrm{CO}_{2}$ emissions and contribute to circular economy. Fast pyrolysis is one well-proved technology to produce bio-oil as intermediate followed by liquid biofuel via hydrogen treatment [1]. During this process, hydrogen treatment is playing a vital role to eliminate oxygen content and promote the quality of primary bio-oil [2]. Applying hydrogen donors either to the co-catalytic fast pyrolysis or in the downstream hydrogen treatment, for instance hydrodeoxygenation (HDO) requires technically and economically feasible hydrogen source. For decades, 
molecular hydrogen has been used as the major hydrogen source in the industrial hydrogen treatment process, because of its high reactivity and facile cracking in the presence of catalysts [3,4]. However, challenges including high cost and safety concerns impede the wide application of molecular hydrogen. Stable and efficient alternative hydrogen sources, as well as the corresponding catalyst for hydrogen donation are urgently necessary, posing one of the most critical bottlenecks limiting the development of liquid biofuels production.

Various alternative organic hydrogen donors have been detailed reviewed in our recent work [5]. Among them, the bio-acids are promising not only as hydrogen donors but also potential chemicals for hydrogen storage [6]. Additionally, the in-situ feature of the hydrogen donation using bio-acids due to that they are existing compounds in bio-oil highly promotes their utilization [2]. There is good literature in plenty reporting the decomposition of respective formic acid and acetic acid respectively over transition metals surfaces [7-9]. Jiang $\mathrm{Z}$ et al [7] predicted the referable decomposition of FA over $\mathrm{Cu}(111)$ to be $\mathrm{HCOOH}$ $\rightarrow \mathrm{HCO} \rightarrow \mathrm{CO}$ over $\mathrm{Cu}$ (111) by DFT. Xinbao et al. [10] reported the decomposition mechanism of AcOH over $\mathrm{Co}$ (111) stepped facet, indicating the reaction pathway follows $\mathrm{CH}_{3} \mathrm{COOH} \rightarrow \mathrm{CH}_{3} \mathrm{CO} \rightarrow \mathrm{CH}_{2} \mathrm{CO} \rightarrow$ $\mathrm{CH}_{2} \rightarrow \mathrm{CH}$. There are other different reaction mechanisms for AcOH decomposition $[8,11,12]$. However, the hydrogen donation behaviour of the bio-acids has been inadequately evaluated. Our recent research demonstrated bio-acids (i.e. acetic acid and formic acid) possess great potential as hydrogen donors for catalytic fast pyrolysis of biomass over Mo (110) facet due to their exothermic property and lower energy barriers during the decomposition [5]. Nevertheless, the pure metals can be hardly applied as sole catalysts in the real practice because they are likely to be rapidly deactivated due to the carbonaceous deposit. Ideally, the metal atoms are evenly highly distributed (single atom layer) on the substrates surface, such that they can remain active throughout the reactions.

Therefore, proper substrate (support) is an essential part for metal based catalysts and regarded to be crucial for the consequent catalytic activity [13]. Studies have reported the bio-acids decomposition over the catalysts with a variety of substrates such as metal oxides [14,15], zeolites [16], as well as the carbon based materials $[17,18]$, wherein CNTs as a sustainable resource are being widely developed as one type of the most promising catalyst substrates because of their thermal stability, carbonaceous deposit resistance and large specific surface area [19-21]. Furthermore, the various functionalization of CNTs including transition metal loading [22], defects and elements doping [23,24], have demonstrated great potential in the redox reactions by achieving a high conversion rate and selectivity to the targeted chemicals [25]. For example, nitrogen doped CNTs is considered to remarkably promote the activity of CNTs by tailoring the local electron property [26]. Regarding the functionalization with loading metals, it has been widely recognized that highly dispersed metal active sites can be achieved on CNTs compared to other substrates (e.g. metal oxides, zeolites etc.) [27].

The bi-functionalized CNTs have been used for a variety of reactions, including the catalytic fast pyrolysis (CFP) of biomass and HDO for producing biofuels [28-30], therefore they can be catalyst candidates used for the in-situ hydrogen donation during those processes. Ding Tian-Yi et al [31] reported conversion of FA over Pd loaded CNTs into $\mathrm{CO}_{2}$ and $\mathrm{H}_{2}$ at room temperature with a high turnover frequency (TOF) of 
$1135 \mathrm{~h}^{-1}$, Nabid R. Mohammad [32] synthesized Ag core Pd shell nanoparticles supported on CNTs without any additives and achieved formic acid dehydrogenation to $\mathrm{CO}_{2}$ with an overall activation energy of $28.28 \mathrm{KJ} / \mathrm{mol}$. Bi Qing-Yuan et al. [33] modified CNTs with nitrogen doping and successfully promoted the TOF higher than $5000 \mathrm{~h}^{-1}$, with almost full conversion of FA. Current literature have revealed that good performance was received from (bi-) functional CNTs in activating bio-acids especially FA, while most research are based on experimental study at room temperatures, with little focus on the elementary reactions, and the detailed catalytic mechanism of bio-acids decomposition and the interactions between each functional component of the CNTs catalyst composite have rarely been revealed in such regard.

In this study, the decomposition of bio-acids (acetic acid and formic acid) for hydrogen donation have been investigated over the functionalized CNTs, focusing on the cleavage of hydrogen related bonds. Ten loading metals (Ni, Mo, Fe, Co, Pt, $\mathrm{Rh}, \mathrm{Ru}, \mathrm{Zn}, \mathrm{Cu}, \mathrm{Pd}$ ) and five types of nitrogen-doped CNT catalysts are compared regarding their binding energy in adsorbing bio-acid molecule $(\mathrm{AcOH})$. The bio-acids are then evaluated in terms of their adsorption process and performance in hydrogen donation over the nitrogen doped CNT catalysts. Bond cleavages are tracked throughout the decomposition of bio-acid molecules over catalysts. The roles of metal loading and different types of nitrogen doping on the hydrogen donation from bio-acid molecules are evaluated. This study predicts the in-situ hydrogen donation behaviour of bio-acids over the novel CNT based catalyst during the biofuels production and is envisioned to provide reference to further catalyst design in the real practice.

\section{Results And Discussion \\ 2.1 Catalyst design}

The catalyst was designed as metal loaded on $\mathrm{N}$ doped carbon nano tubes (metal/N-CNT) where the metals will be active compounds with catalytic support from N-CNT. Ten different transition metals are compared in terms of their consequent adsorption energy, as shown in Fig. 1 and Supplementary Material S2. Acetic acid $(\mathrm{AcOH})$ was selected as the model compound due to its abundance in bio-oil. The adsorption energy of AcOH over the pure metal facets [5] is also shown for comparison in the Fig. 1. The results indicate that $\mathrm{AcOH}$ had higher adsorption energy over all the catalytic sites compared to pure metal facets, implying stronger interaction between the molecule and the CNT based catalysts.

Comparing the ten metals indicated that $\mathrm{Mo}$ and $\mathrm{Pt}$ loadings shows the strongest binding energies with $\mathrm{AcOH}$, with an additional consideration of economic perspective, Mo was selected as the most suitable loaded metal for the designed catalysts in this study.

For the selection of CNT, the adsorption energy of AcOH onto a variety of CNT based catalysts are compared in Table 1. The aforementioned two common types of $\mathrm{N}$-CNT models $\left(\mathrm{N}_{\mathrm{p}}-\mathrm{CNT}\right.$ and $\left.\mathrm{N}_{\mathrm{g}}-\mathrm{CNT}\right)$ are established and demonstrated in Fig. 2, along with the intact CNT model. 
Table 1

Adsorption energy of AcOH onto (functionalised) CNTs

\begin{tabular}{|c|c|c|c|c|c|c|}
\hline Active site (catalyst) & $\begin{array}{l}\mathrm{Mo} / \mathrm{N}_{\mathrm{p}}- \\
\mathrm{CNT}\end{array}$ & $\begin{array}{l}\mathrm{Mo} / \mathrm{N}_{\mathrm{g}}- \\
\mathrm{CNT}\end{array}$ & Mo/CNT & $\begin{array}{l}\mathrm{N}_{\mathrm{p}}- \\
\mathrm{CNT}\end{array}$ & $\begin{array}{l}\mathrm{N}_{\mathrm{g}}^{-} \\
\mathrm{CNT}\end{array}$ & CNT \\
\hline $\begin{array}{l}\text { Adsorption Energy of } \mathrm{AcOH} \\
(\mathrm{eV})\end{array}$ & -1.76 & -1.61 & -1.72 & $-0.73 *$ & $-0.73 *$ & $-0.63^{*}$ \\
\hline
\end{tabular}

Results showed that the intact CNT as catalyst led to the lowest adsorption energy (close to physical adsorption, distance larger than $3 \AA$ ) of $\mathrm{AcOH}$. N-CNTs gave rise to slightly larger adsorption energy, but no obvious difference could be observed among the different doping types. The modelling results revealed Mo improved the adsorption energy of $\mathrm{AcOH}$ dramatically compared with the adsorption onto non-metal loading CNTs, confirming the binding promotion effect of Mo to the AcOH adsorption, in line with recent study [5]. Over Mo/ $\mathrm{N}_{\mathrm{p}}-\mathrm{CNT}$, AcOH exhibited higher binding energy, ascribed to the unpaired electron of pyridinic $\mathrm{N}$ acts as electron acceptor (Lewis acid), such that reinforces the binding between the catalyst and adsorbate molecule [34]. This is also confirmed by the lower adsorption energy of $\mathrm{AcOH}$ molecule over Mo/CNT. The adsorption energy was obviously declined by the Mo/ $\mathrm{N}_{\mathrm{g}}-\mathrm{CNT}$. This probably because the aforementioned electron donation property of the graphitic nitrogen offsets the acidity, giving rise to weaker binding between the $\mathrm{AcOH}$ molecule and $\mathrm{Mo} / \mathrm{N}_{\mathrm{g}}-\mathrm{CNT}$ catalyst [26]. It is also found that the $\mathrm{N}_{\mathrm{p}}$-CNT and $\mathrm{N}_{\mathrm{g}}$-CNT exhibited different acid and base effects on $\mathrm{AcOH}$ adsorption only in the present of metal atom Mo, this is ascribed to the synergistic effects between element doping and loading metal, in line with the reported results in literature $[35,36]$. It is thus hypothesized that the two types of $\mathrm{N}$ doping would lead to different catalytic effects on the decomposition of bio-acids.

\subsection{AcOH as hydrogen donor over Mo/N-CNTs}

Different adsorption configurations of $\mathrm{AcOH}$ over the two types of catalysts, $\mathrm{Mo} / \mathrm{N}_{\mathrm{p}}-\mathrm{CNT}$ and $\mathrm{Mo} / \mathrm{N}_{\mathrm{g}}-\mathrm{CNT}$, were compared in Table 2. The labelled atoms for $\mathrm{AcOH}$ and the Bond Dissociation Energies (BDEs) of each bond are illustrated in Fig. 3. For both cases, $\mathrm{AcOH}$ bonded onto the catalytic sites by chemical adsorption through $\mathrm{C}_{\beta}-\mathrm{Mo}, \mathrm{O}_{\mathrm{a}}-\mathrm{Mo}$, and $\mathrm{O}_{\beta}-\mathrm{Mo}$, and by weak binding through $\mathrm{C}_{\mathrm{a}}-\mathrm{Mo}$, where $\mathrm{Mo} / \mathrm{N}_{\mathrm{p}}-\mathrm{CNT}$ resulted in higher binding energy in all the chemical adsorption circumstances. Interestingly, dissociative adsorption was observed when $\mathrm{AcOH}$ bonded to the $\mathrm{Mo} / \mathrm{N}_{\mathrm{p}}-\mathrm{CNT}$ through $\mathrm{O}_{\beta}-\mathrm{Mo}$, where the molecule decomposed into hydroxyl and acetyl (Ac) during the adsorption. The dissociative adsorption is common for molecular hydrogen adsorption over transition metals [4], but it is the first time observed for the AcOH adsorption, and has not been observed onto Mo surface in our recent study, neither over $\mathrm{Mo} / \mathrm{N}_{\mathrm{g}}-\mathrm{CNT}$ [5]. The dissociative adsorption simultaneous led to the biggest adsorption energy of $-2.61 \mathrm{eV}$ for $\mathrm{Mo} / \mathrm{N}_{\mathrm{p}}-\mathrm{CNT}$ through $\mathrm{O}_{\beta}$-Mo bond. The same $\mathrm{O}_{\beta}$-Mo bond also led to the biggest adsorption energy of $-2.11 \mathrm{eV}$ when $\mathrm{AcOH}$ molecule adsorbed on $\mathrm{Mo} / \mathrm{N}_{\mathrm{g}}-\mathrm{CNT}$. The difference between the adsorption energies of $\mathrm{AcOH}$ respectively onto $\mathrm{N}_{\mathrm{g}}$ and $\mathrm{N}_{\mathrm{p}}$ doped catalyst links to their electron donation and acceptation properties. 
Table 2

Adsorption energy of $\mathrm{AcOH}$ onto Mo/N-CNTs with different configurations

\begin{tabular}{|lllll|}
\hline Adsorption Energy of $\mathrm{AcOH}(\mathrm{eV})$ & $\mathrm{C}_{\mathrm{a}}-\mathrm{Mo}$ & $\mathrm{C}_{\boldsymbol{\beta}}-\mathrm{Mo}$ & $\mathrm{O}_{\mathrm{a}}-\mathrm{Mo}$ & $\mathrm{O}_{\boldsymbol{\beta}}-\mathrm{Mo}$ \\
\hline $\mathrm{Mo} / \mathrm{N}_{\mathrm{p}}$-CNT & $-0.58^{*}$ & -2.41 & -1.76 & -2.61 \\
\hline $\mathrm{Mo} / \mathrm{N}_{\mathrm{g}}-\mathrm{CNT}$ & $-0.75^{*}$ & -1.99 & -1.61 & -2.11 \\
\hline *only stable weak adsorption observed & & & \\
\hline
\end{tabular}

The most favourable reaction pathways of $\mathrm{AcOH}$ decomposition over $\mathrm{Mo} / \mathrm{N}_{\mathrm{p}}$-CNT are shown in Fig. 4, which are determined based on the cleavage energy calculation for each bond inside the acid molecule, as well as inside the lower fraction structures (the lowest energy barrier value among all parallel bonds cleavage are shown). The modelling results predicted that the decomposition of $\mathrm{AcOH}$ started with the dissociative adsorption, which produced two lower fractions of hydroxyl and acetyl (Ac). The acetyl further cracked into $\mathrm{CO}$ and methyl with a small energy barrier of $0.32 \mathrm{eV}$ and reaction energy of $-0.68 \mathrm{eV}$. Further decomposition of the methyl released three hydrogens in sequence with the energy barriers of $1.74 \mathrm{eV}, 1.47 \mathrm{eV}$ and $2.54 \mathrm{eV}$ respectively. Another hydrogen cleaved and released from the hydroxyl with an energy barrier of $2.03 \mathrm{eV}$. It is also found that over $\mathrm{Mo} / \mathrm{N}_{\mathrm{p}}-\mathrm{CNT}$, majority of elementary steps amid the favourable reaction pathway of $\mathrm{AcOH}$ decomposition are endothermic, except the thermal dynamic favoured C-C cleavage.

Over the $\mathrm{Mo} / \mathrm{N}_{\mathrm{g}}-\mathrm{CNT}$ (Fig. 5), AcOH seems remained intact after adsorption, but also underwent facile decomposition to produce Ac and hydroxyl with a small energy barrier of $0.21 \mathrm{eV}$, and this process had an exothermic energy of $-0.77 \mathrm{eV}$. The $\mathrm{C}-\mathrm{C}$ bond in Ac group over the $\mathrm{Mo} / \mathrm{N}_{\mathrm{g}}-\mathrm{CNT}$ was much reinforced, such that the $\mathrm{C}=\mathrm{O}$ bond cleaved firstly, giving rise to the structure of $\mathrm{CH}_{3}-\mathrm{C}$, which decomposed into methyl and carbon atom in next step also with big energy barrier of $2.47 \mathrm{eV}$. The cleavage of $\mathrm{C}=0$ prior to $\mathrm{C}-\mathrm{C}$ is also found for the $\mathrm{AcOH}$ decomposition over Mo slab in our previous research [5]. The release of hydrogen atoms from methyl over Mo/ $\mathrm{N}_{\mathrm{g}}$-CNT had the energy barriers of $0.36 \mathrm{eV}, 0.72 \mathrm{eV}$ and $3.74 \mathrm{eV}$ respectively. Besides, the cleavage of the hydroxyl hydrogen requires additional energy of $1.58 \mathrm{eV}$.

In comparison with the free molecular decomposition of $\mathrm{AcOH}$ [5], shown in Fig. 3, the cleavage energy of each bond in $\mathrm{AcOH}$ has been significantly decreased, implying that both Mo/N-CNT catalysts facilitate the decomposition of $\mathrm{AcOH}$. The modelling results predict hydroxyl cleavage occurs at the beginning of the $\mathrm{AcOH}$ decomposition over both types of Mo/N-CNTs, this is different from the pathways over pure metal facets e.g. Mo and Rh [5,37], specifically, the formation of acetate group is supressed at the beginning of reaction, and the donation of methyl hydrogens occurs as final steps in both cases.

Driven by the electrophilicity (electron accepter) property, $\mathrm{Mo} / \mathrm{N}_{\mathrm{p}}-\mathrm{CNT}$ results in barrier-free dissociation during the $\mathrm{AcOH}$ adsorption, while $\mathrm{Mo} / \mathrm{N}_{\mathrm{g}}-\mathrm{CNT}$ leads to a small energy barrier for the same decomposition. The modelling predicts different following favourable decomposition pathways of $\mathrm{AcOH}$ 
decomposition over two Mo/N-CNTs catalysts. Mo/ $\mathrm{N}_{\mathrm{p}}$-CNTs favours C-C cleavage, where the energy barrier is dramatically lowered from $4.22 \mathrm{eV}$ to $0.32 \mathrm{eV}$ compared to the reactions over pure Mo slab. This gives rise to a commonly reported favourable reaction pathway of $\mathrm{AcOH}$ decomposition [13,38, 39], with the merit that little hurdles before the hydrogen donation. While the cleavage of the four hydrogens from the lower fragments of methyl and hydroxyl is mostly endothermic process with higher energy barriers. This may ease methane and $\mathrm{CO}$ formation while the hydrogen donation $[39,40]$. In contrast, the releasing of methyl hydrogen and the hydroxyl hydrogen show smaller energy barriers over $\mathrm{Mo} / \mathrm{N}_{\mathrm{g}}-\mathrm{CNT}$, implying the dedicated function of $\mathrm{Mo} / \mathrm{N}_{\mathrm{g}}-\mathrm{CNT}$ in facilitating the dissociation of $\mathrm{C}-\mathrm{H}$ bond. However, the early stage decomposition steps such as $\mathrm{C}-\mathrm{O}_{a}$ and $\mathrm{C}-\mathrm{C}$ with higher energy barriers would more likely hinder the following hydrogen donation.

\subsection{FA as hydrogen donor over Mo/N-CNTs}

The adsorption of formic acid (FA) over Mo/ $\mathrm{N}_{\mathrm{p}}-\mathrm{CNT}$ and $\mathrm{Mo} / \mathrm{N}_{\mathrm{g}}-\mathrm{CNT}$ in a variety of configurations was modelled and the adsorption energy were compared in Table 3. The atoms for FA and the BDEs of its bonds are shown in Fig. 6 . The FA molecule bound to the catalyst via C-Mo bond led to the highest adsorption energy among all the configurations; $-3.54 \mathrm{eV}$ for $\mathrm{Mo} / \mathrm{N}_{\mathrm{p}}-\mathrm{CNT}$ and $-2.75 \mathrm{eV}$ for $\mathrm{Mo} / \mathrm{N}_{\mathrm{g}}-\mathrm{CNT}$, followed by the binding through $\mathrm{O}_{\mathrm{a}}-\mathrm{Mo}$ for $-1.75 \mathrm{eV}$ and $-1.55 \mathrm{eV}$ respectively. $\mathrm{O}_{\beta}-\mathrm{Mo}$ gave rise to the lowest adsorption energies of $-0.81 \mathrm{eV}$ and $-1.15 \mathrm{eV}$ for each catalyst. Dissociative adsorption was observed for FA adsorption over both catalysts, which occurs to $\mathrm{AcOH}$ but solely over $\mathrm{Mo} / \mathrm{N}_{\mathrm{p}}-\mathrm{CNT}$. The most favourable reaction pathways for FA adsorption in both cases are summarized and depicted in Fig. 7 and Fig. 8 respectively.

Table 3

Adsorption energy of FA onto Mo/N-CNTs with different configurations

\begin{tabular}{|llll|}
\hline Adsorption Energy of FA (eV) & C-Mo & $\mathbf{O}_{\mathrm{a}}-\mathrm{Mo}$ & $\mathrm{O}_{\boldsymbol{\beta}}-\mathrm{Mo}$ \\
\hline $\mathrm{Mo} / \mathrm{N}_{\mathrm{p}}-\mathrm{CNT}$ & -3.54 & -1.74 & $-0.81^{*}$ \\
\hline $\mathrm{Mo} / \mathrm{N}_{\mathrm{g}}-\mathrm{CNT}$ & -2.75 & -1.55 & -1.15 \\
\hline *only stable weak adsorption observed & & \\
\hline
\end{tabular}

Over $\mathrm{Mo} / \mathrm{N}_{\mathrm{p}}$-CNT, the dissociation amid the adsorption of FA led to the simultaneous barrier-free cleavage of $\mathrm{C}-\mathrm{H}$ and $\mathrm{C}-\mathrm{O}_{\beta}$ with the adsorption energy of $-3.54 \mathrm{eV}$, producing two lower fragments of bonded $\mathrm{CO}$ and hydroxyl group with direct $\mathrm{H}$ donation. The other hydrogen cleavage from the hydroxyl group showed $1.98 \mathrm{eV}$ intrinsic energy barrier with the reaction energy of $0.41 \mathrm{eV}$. Over $\mathrm{Mo} / \mathrm{N}_{\mathrm{g}}-\mathrm{CNT}$, FA molecule also underwent the similar dissociative adsorption without any energy barriers, producing aldehyde group and hydroxyl. The aldehyde hydrogen was then cleaved with a small energy barrier for $0.36 \mathrm{eV}$, where the reaction is exothermic with the reaction energy of $-1.34 \mathrm{eV}$. The hydroxyl cleavage overcame an energy 
barrier of $1.57 \mathrm{eV}$ for releasing the other hydrogen atom, and this is also an exothermic process with the reaction energy of $-0.49 \mathrm{eV}$.

The reactions involved in FA decomposition over both catalysts are facilitated by lower intrinsic energy barriers compared to the free molecule scenario (Fig. 6). The modelling also predicts that the Mo/N-CNTs give rise to different favourable reaction pathways of FA decomposition in comparison with common catalysts [18,41,42]; instead of the formation of carboxylic or formate intermediates, dehydroxyl reaction occurs at the beginning with the dissociative adsorption in this study, with the particular facility of the hydrogen donation. The dehydroxyl reaction was also reported over the $\mathrm{Cu}$ (111) facet, but with higher energy barrier [7]. Compared to the decomposition of FA over pure Mo [5], nitrogen doped CNTs exhibit better performance in terms of facilitating hydrogen donation by lowering the energy barriers and less reaction steps.

The two hydrogen atoms in FA molecule show quite different readiness for donation in both cases. Modelling results predict that the hydrogen connected to $C$ is more readily to cleave over Mo/N-CNTs compared to the hydroxyl hydrogen. Especially, $\mathrm{N}_{\mathrm{p}}$ doped CNT induces barrier-free hydrogen cleavage during the adsorption, which is comparable to the hydrogen donation performance of $\mathrm{H}_{2}$. The $\mathrm{C}-\mathrm{H}$ bond cleavage was unfavourable in some circumstances [5,43], but it turns to be much facile over both catalysts in this study. In comparison, the cleavage of hydroxyl hydrogen is more difficult than aldehyde hydrogen, giving rise to the peak energy barrier of FA decomposition in both cases. It is found that $\mathrm{Mo} / \mathrm{N}_{\mathrm{g}}$ CTN led to lower energy barrier for the cleavage of hydroxyl hydrogen than Mo/ $\mathrm{N}_{\mathrm{p}}-\mathrm{CTN}$. But it also noteworthy that the dissociative adsorption energy of FA over Mo/ $\mathrm{N}_{\mathrm{p}}$-CNT much higher than that for $\mathrm{Mo} / \mathrm{N}_{\mathrm{g}}-\mathrm{CNT}$, which in turn could potentially contribute to the consequent cleave of hydroxyl and its hydrogen donation by preventing the formation $\mathrm{H}_{2} \mathrm{O}$ and $\mathrm{CO}$ [18].

When comparing the hydrogen donation potential of $\mathrm{FA}$ and $\mathrm{AcOH}$, although FA has less hydrogen atoms than $\mathrm{AcOH}$, the modelling results revealed that greater potential for in-situ hydrogen donation is gained by FA over both Mo/N-CNTs catalysts. This is mainly due to the energy released during the dissociative adsorption occurs at the initial step of interaction of FA on $\mathrm{Mo} / \mathrm{N}_{\mathrm{g}}$-CNT surfaces.

\subsection{Electron density difference (EDD) and atomic charge analysis for secondary decomposition of typical lower fragments}

The reaction modelling results indicate that $\mathrm{Mo} / \mathrm{N}_{\mathrm{g}}-\mathrm{CNT}$ and $\mathrm{Mo} / \mathrm{N}_{\mathrm{p}}-\mathrm{CNT}$ show different performance in accelerating hydrogen donation by affecting the decomposition of typical groups. Specifically, $\mathrm{Mo} / \mathrm{N}_{\mathrm{g}}{ }^{-}$ CNT is capable of preferentially activating bonds of $\mathrm{O}-\mathrm{H}$ and $\mathrm{C}-\mathrm{H}$, and $\mathrm{Mo} / \mathrm{N}_{\mathrm{p}}-\mathrm{CNT}$ gives rise to the readily cleavage of bond $\mathrm{C}-\mathrm{C}$. To reveal catalysts effects on reactant molecules, electron density difference (EDD) analysis was carried out to the typical intermediate groups of the acetyl, methyl and hydroxyl over both 
catalysts respectively, as shown in Fig. 9 to Fig. 11. Atomic charge was also calculated and assigned to each atom as an indicator for interatomic covalency.

The analysis reveals $\mathrm{N}_{\mathrm{p}}$ and $\mathrm{N}_{\mathrm{g}}$ give rise to different electronegativity effects towards the lower fragment groups, and this is in consistent with the catalytic property of both doping types. For the acetyl over $\mathrm{Mo} / \mathrm{N}_{\mathrm{p}}$-CNT, electron loss and enrichment were both found around $\mathrm{C}_{\beta}$, and mainly electron enrichment around methyl group was observed. As a result, the $C_{\beta}$ and methyl group tend to be electronic neutral prior to the cleavage, due to the group atomic charge (for 0.01 and 0.00 respectively). In the case of $\mathrm{Mo} / \mathrm{N}_{\mathrm{g}}$-CNT, Mo had less electron loss but there was even more electron enrichment to make the $\mathrm{C}_{\beta}$ absolute electric neutral (charge $=0.00$ ), owing to the less electron enrichment on $\mathrm{N}_{\mathrm{g}}$ and the delocalized electron compensation from $\mathrm{N}_{\mathrm{g}}$. However, less electrons was found migrating to the methyl group, giving rise to an overall positive charge $(0.08)$ for the methyl in acetyl over $\mathrm{Mo} / \mathrm{N}_{\mathrm{g}}-\mathrm{CNT}$. The results imply that methyl group cleavage in acetyl tends to be homolytic cleavage (evidenced by the atomic charge analyses of the corresponding transition states shown in S3 in the Supplementary Material), which is much more facilitated by $\mathrm{Mo} / \mathrm{N}_{\mathrm{p}}$-CNT, in line with the modelling results. The catalyst enables more electrons loss on $\mathrm{Mo}$, therefore reinforces the $\mathrm{Mo}-\mathrm{C}_{\beta}$ bond. Simultaneously, it gives rise to obvious electron enrichment on $\mathrm{C}_{\beta}$ and methyl group, which eventually reduces the strength of $\mathrm{C}-\mathrm{C}$ bond and makes it more readily to cleave. This mechanism is supposed to also contribute to the stabilisation of Mo- $\mathrm{O}_{\beta}$ bond and consequent dissociative adsorption of $\mathrm{AcOH}$ over $\mathrm{Mo} / \mathrm{N}_{\mathrm{p}}-\mathrm{CNT}$, where the $\mathrm{C}-\mathrm{O}_{\beta}$ cleaves straightforwardly.

Regarding the adsorbed methyl, electron enrichment around carbon was found when it was adsorbed on $\mathrm{Mo} / \mathrm{N}_{\mathrm{p}}-\mathrm{CNT}$, which results from the electron loss of Mo. Over Mo/ $\mathrm{N}_{\mathrm{g}}-\mathrm{CNT}$, methyl group in bulk gained more electrons, revealing the effect of the delocalization electron from graphitic doping of $\mathrm{N}$. It is noteworthy that in this case not only the carbon but also the hydrogen atoms benefit from the electron enrichment, resulting in nearly electric neutrality of the hydrogen atoms, as with those in $\mathrm{H}_{2}$ molecule, such that they are readily to cleave and donate. The result indicates methyl is more likely to donate hydrogen through homolytic cleavage (evidenced by the atomic charge analyses of the corresponding transition states in S3) over Mo/ $\mathrm{N}_{\mathrm{g}}-\mathrm{CNT}$, and the reaction benefits from the electron enrichment between $\mathrm{C}-\mathrm{H}$.

For the adsorbed hydroxyl, more electron migration to the hydrogen atom was found over $\mathrm{Mo} / \mathrm{N}_{\mathrm{g}}-\mathrm{CNT}$, as shown in Fig. 11. The cleavage of hydroxyl $\mathrm{H}$ was thus facilitated compared to the case of $\mathrm{Mo} / \mathrm{N}_{\mathrm{p}}-\mathrm{CNT}$. Nevertheless, even though Mo had similar electron loss as with it binding to methyl group, the hydroxyl hydrogen did not show electric neutral but apparent positive charged in both cases. This may because of the large electronegativity of oxygen, resulting in higher energy barriers for hydroxyl $\mathrm{H}$ cleavage than methyl $\mathrm{H}$, in line with the reaction modelling results shown in Fig. 4 and Fig. 5. Besides, it is found that the cleavage of hydroxyl $\mathrm{H}$ over both catalysts tends to be homolytic cleavage, which is evidenced by the atomic charge analysis to the corresponding transition states, as shown in S3 in the Supplementary Material. 
The homolytic cleavages during acid decomposition are based on electron enrichment. The results of EDD analyses in this study imply Mo/ $\mathrm{N}_{\mathrm{p}}-\mathrm{CNT}$ may facilitate the $\mathrm{C}-\mathrm{C}$ cleavage, and $\mathrm{Mo} / \mathrm{N}_{\mathrm{g}}-\mathrm{CNT}$ favours the cleavage of $\mathrm{H}$ contained bonds, eventually benefiting the in-situ hydrogen donation.

\section{Conclusions}

This study provided predictions on hydrogen donation behaviour of bio-acids over the nitrogen doped CNTs by DFT modelling. Ten different metal loadings and six types of CNT based substrates were modelled. Adsorption modelling indicated $\mathrm{Mo} / \mathrm{N}_{\mathrm{p}}$-CNT catalyst led to the strongest binding with the adsorbed acid molecule, followed by Mo/CNT and Mo/ $\mathrm{N}_{\mathrm{g}}-\mathrm{CNT}$. The modelling of the decomposition of $\mathrm{AcOH}$ and FA was carried out based on the most common types of nitrogen doped CNTs, i.e. Mo/ $\mathrm{N}_{\mathrm{p}}-\mathrm{CNT}$ and $\mathrm{Mo} / \mathrm{N}_{\mathrm{g}}-\mathrm{CNT}$, with the emphasis on the hydrogen related bonds cleavage. The modelling results revealed that Mo/N-CNTs significantly lowered the decomposition energy barriers for both $\mathrm{AcOH}$ and FA, while different types of $\mathrm{N}$ doping led to different reaction pathways; the most favourable reaction pathway for the decomposition of $\mathrm{AcOH}$ over $\mathrm{Mo} / \mathrm{N}_{\mathrm{p}}$-CNT was $\mathrm{CH}_{3} \mathrm{COOH} \rightarrow \mathrm{CH}_{3} \mathrm{CO} \rightarrow \mathrm{CH}_{3} \rightarrow \mathrm{CH}_{2} \rightarrow \mathrm{CH} \rightarrow \mathrm{C}$, and was $\mathrm{CH}_{3} \mathrm{COOH} \rightarrow \mathrm{CH}_{3} \mathrm{CO} \rightarrow \mathrm{CH}_{3} \mathrm{C} \rightarrow \mathrm{CH}_{3} \rightarrow \mathrm{CH}_{2} \rightarrow \mathrm{CH}_{1} \rightarrow \mathrm{C}$ over the Mo/ $\mathrm{N}_{\mathrm{g}}$-CNT. It was found that the hydrogen donation of $\mathrm{AcOH}$ was hindered by the high energy barriers of either the hydrogen releasing steps or the prior steps in both cases, except the hydroxyl hydrogen was released readily by $\mathrm{Mo} / \mathrm{N}_{\mathrm{g}}-\mathrm{CNT}$. In contrast, barrier-free hydrogen donation was observed during the dissociative adsorption of FA through $\mathrm{HCOOH} \rightarrow \mathrm{H}+\mathrm{CO}+\mathrm{OH}$ over $\mathrm{Mo} / \mathrm{N}_{\mathrm{p}}-\mathrm{CNT}$. FA experienced similar dissociative adsorption over $\mathrm{Mo} / \mathrm{N}_{\mathrm{g}}-\mathrm{CNT}$ through $\mathrm{HCOOH} \rightarrow \mathrm{HCO}+\mathrm{OH}$, and the formyl hydrogen can be released with low energy barriers of $0.36 \mathrm{eV}$. The hydroxyl hydrogen cleavage showed larger energy barriers but would benefit from the exothermic adsorption of FA over both catalysts. Modelling results indicated FA had the superiority for hydrogen donation over both Mo/N-CNT catalysts, mainly ascribed to the facile donation of formyl hydrogen. Further electron analyses revealed that effective decomposition of bio-acids was dominated by homolytic cleavage; Mo/ $\mathrm{N}_{\mathrm{p}}$-CNT gave rise to the electron enrichment to $\mathrm{C}-\mathrm{C}$ bond and facilitated its cleavage, while $\mathrm{Mo} / \mathrm{N}_{\mathrm{g}}-\mathrm{CNT}$ promoted the homolytic cleavage of $\mathrm{C}-\mathrm{H}$ and $\mathrm{O}-\mathrm{H}$ by more electron enrichment on $\mathrm{H}$, in line with the reaction modelling.

\section{Methods}

\subsection{Computational details}

The first-principle density functional theory plus dispersion (DFT-D) calculations were implemented in the Cambridge Sequential Total Energy Package (CASTEP), and models were established in Materials Studio 2017 R2 from BIOVIA [44, 45]. The generalized gradient corrected approximation (GGA) [46] treated by the Perdew - Burke - Ernzerhof (PBE) exchange-correlation potential with long-range dispersion correction via Grimme's scheme was used to calculate the exchange-correlation energy [47]. The On-the-fly generated (OTFG) ultrasoft pseudopotential was employed as the scheme in the representation of reciprocal space for all the elements $[48,49]$. The plane-wave cut-off energy was set to $600 \mathrm{eV}$ for all the calculations 
based on its independence test (Supplementary Material S1). The Brillouin zone was sampled using a $2 \times$ $1 \times 4$ Monkhorst-Pack k-point (spacing of $0.03 \AA^{-1}$ ) with a smearing of $0.1 \mathrm{eV}$, based on its independence test (Supplementary Material S1). The self-consistent field (SCF) tolerance was set to $10^{-6} \mathrm{eV} /$ atom. All the modelling was performed with a convergence threshold of $10^{-5} \mathrm{eV} /$ atom on energy, $0.03 \mathrm{eV} / \AA$ on maximum force, and $10^{-3} \AA$ on the maximum displacement. No symmetry constraint was used for any modelling.

All the models were based on a two units CNT supercell with a diameter of $9.5 \AA .15 \AA$ vacuum region was created above top of the CNT. Geometry optimization was implemented to every model before energy was calculated. Energy of all the geometries was calculated at OK in the DFT investigation. The transition state (TS) was completely determined by the LST/QST method, and the TSs for the dominated reaction steps were confirmed by the unique imaginary frequency. Hirshfeld charge was calculated for atomic electron analysis. The adsorption energy $E_{a d}$ was determined by Eq. 1, where $E_{\text {catalyst }}, E_{\text {adsorbate }}$ and $E_{\text {adsorbate/catalyst }}$ are the total energies of clean catalyst, free adsorbate molecule and catalyst with adsorbed molecule respectively. The energy barriers of reactions $E_{\text {barrier }}$ were determined by the difference between the energies of transition state and reactant, as shown in Eq. 2, where $E_{\text {transition state }}$ and $E_{\text {reactant }}$ are the total energies of the transition state and reactant of a reaction, respectively.

$E_{\text {ad }}=E_{\text {adsorbate/catalyst }}-\left(E_{\text {catalyst }}+E_{\text {adsorbate }}\right)$ Eq. 1

$E_{\text {barrier }}=E_{\text {transition state }}-E_{\text {reactant }}$ Eq. 2

The electron density difference (EDD) was determined by Eq. 3.

$\Delta \rho=\rho_{\text {adsorbate@CNT }}-\left(\rho_{\text {adsorbate }}+\rho_{\mathrm{CNT}}\right)$ Eq. 3

where $\rho_{\text {adsorbate@CNT }}$ is the electron density of the total adsorbate + CNT system, and $\rho_{\text {adsorbate }}$ and $\rho_{\text {CNT }}$ are the unperturbed electron densities of the adsorbate and the CNT structure, respectively.

\subsection{Catalyst (substrate) selection}

As aforementioned, nitrogen doped CNTs (N-CNTs) were investigated since they could potentially promote the activity of CNTs. Basically, there are four types of N-CNTs (as shown in Fig. 12): graphitic $N$ ( $\mathrm{N}_{\mathrm{g}}$-CNTs), (vacancy) pyridinic $\mathrm{N}$ (referred as pyridinic nitrogen in this work, $\mathrm{N}_{\mathrm{p}}$-CNTs), pyrrolic $\mathrm{N}$ and pyridinic $\mathrm{N}-\mathrm{O}$. Synthesis investigation of $\mathrm{N}$-CNTs indicates that $\mathrm{N}_{\mathrm{g}}$-CNTs and $\mathrm{N}_{\mathrm{p}}$-CNTs are the most common doping types $[50,51]$. Pyridinic atoms normally locate at the edges or in the vacancy of the CNT surface and bond to two carbon atoms, and the three sp2 orbitals are occupied by four electrons, where two electrons are used to form two $\delta$ bonds with carbon atoms, and the other two hybridized electrons form a lone pair. The remaining electron in $N_{p}$ joins in the adjacent carbon atoms to form $\pi$ bond. The lone electron pair would endow the $\mathrm{N}_{\mathrm{p}}$-CNTs with Lewis basicity, while the $\pi$ electron acts as electron acceptor $[35,52,53]$. $N_{g}$ have similar sp2 hybridization as that for $N_{p}$, four orbitals are occupied by only four electrons to form three $\delta$ bonds and one $\pi$, and the fifth electron is not accommodated in a bonding 
orbitals so that is in higher energy state and delocalized from the $\mathrm{N}$ site, functioning as an electron donor $[26,54,55]$.

It has been found that the presence of various nitrogen doping on CNTs gives rise to different catalytic effects due to their basicity and acidity $[57,58]$. The effects of $N_{g}$ and $N_{p}$ doping types on the adsorption and decomposition of bio-acids would be specially investigated in this study.

\section{Abbreviations}

CFP

Catalytic fast pyrolysis

DFT

Density Functional Theory

EDD

electron density difference

$\mathrm{N}-\mathrm{CNTS}$

Nitrogen doped carbon nano tubes

$\mathrm{N}_{\mathrm{g}}$

graphitic-N

$\mathrm{N}_{\mathrm{p}}$

pyridinic-N

\section{Declarations}

\section{Ethics approval and consent to participate}

Not participate.

\section{Consent for publication}

All authors agree with the content and submission of this original research, and we confirm that the manuscript is not being considered for publication elsewhere.

\section{Competing interests}

The authors declare no competing interest.

\section{Funding}

The authors would like to acknowledge financial support from the Leverhulme Trust Research Grant (RPG-2017-254) and EPSRC First Grant (EP/R010986/1).

\section{Authors' contributions}


The first author carried out the calculations and drafting the manuscript; the second author (corresponding author) contributed on the research idea, proof reading and finalising the manuscript; the third author contributed on proof reading of the manuscript.

\section{Acknowledgements}

The authors are also grateful for computational support from the UK Materials and Molecular Modelling Hub, which is partially funded by EPSRC (EP/P020194/1), for which access was obtained via the UKCP consortium and funded by EPSRC grant ref EP/P022561/1.

\section{Availability of data and material}

All data generated in the present study are included in this manuscript and the supplementary material.

\section{References}

[1] X. Zhang, Essential scientific mapping of the value chain of thermochemically converted secondgeneration bio-fuels, Green Chem. 18 (2016). doi:10.1039/c6gc02335e.

[2] L. Garcia, R. French, S. Czernik, E. Chornet, Catalytic steam reforming of bio-oils for the production of hydrogen: effects of catalyst composition, Appl. Catal. A Gen. 201 (2000) 225-239. doi:http://dx.doi.org/10.1016/S0926-860X(00)00440-3.

[3] A. CORMA, G. HUBER, L. SAUVANAUD, P. OCONNOR, Processing biomass-derived oxygenates in the oil refinery: Catalytic cracking (FCC) reaction pathways and role of catalyst, J. Catal. 247 (2007) 307327. doi:10.1016/j.jcat.2007.01.023.

[4] M. Pozzo, D. Alfè, Hydrogen dissociation and diffusion on transition metal (=Ti, Zr, V, Fe, Ru, Co, Rh, $\mathrm{Ni}, \mathrm{Pd}, \mathrm{Cu}, \mathrm{Ag}$ )-doped Mg(0001) surfaces, Int. J. Hydrogen Energy. 34 (2009) 1922-1930. doi:10.1016/j.ijhydene.2008.11.109.

[5] J. Zhang, X. Zhang, A. Osatiashtiani, A. Bridgwater, Hydrogen donation of bio-acids over transition metal facets: A Density Functional Theory study, Appl. Catal. A Gen. (2019) 117218. doi:10.1016/j.apcata.2019.117218.

[6] K. Müller, K. Brooks, T. Autrey, Hydrogen Storage in Formic Acid: A Comparison of Process Options, Energy \& Fuels. 31 (2017) 12603-12611. doi:10.1021/acs.energyfuels.7b02997.

[7] Z. Jiang, P. Qin, T. Fang, Decomposition mechanism of formic acid on Cu (111) surface: A theoretical study, Appl. Surf. Sci. 396 (2017) 857-864. doi:10.1016/j.apsusc.2016.11.042.

[8] C. Hu, S.-W. Ting, K.-Y. Chan, W. Huang, Reaction pathways derived from DFT for understanding catalytic decomposition of formic acid into hydrogen on noble metals, Int. J. Hydrogen Energy. 37 (2012) 15956-15965. doi:10.1016/j.ijhydene.2012.08.035. 
[9] Y. Huang, X. Dong, Y. Yu, M. Zhang, Comparative Kinetic Monte Carlo Study of Acetic Acid Decomposition to Surface Carbon Species and Undesirable Byproducts on $\mathrm{Pd}(100)$ and $\mathrm{Pd} / \mathrm{Au}(100)$ from Density Functional Theory-Based Calculations, J. Phys. Chem. C. 121 (2017) 26733-26741. doi:10.1021/acs.jpcc.7b05072.

[10] X. Li, S. Wang, Y. Zhu, G. Yang, P. Zheng, DFT study of bio-oil decomposition mechanism on a Co stepped surface: Acetic acid as a model compound, Int. J. Hydrogen Energy. 40 (2015) 330-339. doi:10.1016/j.ijhydene.2014.11.004.

[11] K.I. Gursahani, R. Alcalá, R.D. Cortright, J.A. Dumesic, Reaction kinetics measurements and analysis of reaction pathways for conversions of acetic acid, ethanol, and ethyl acetate over silica-supported Pt, Appl. Catal. A Gen. 222 (2001) 369-392. doi:10.1016/S0926-860X(01)00844-4.

[12] R. Alcala, J.W. Shabaker, G.W. Huber, M.A. Sanchez-Castillo, J.A. Dumesic, Experimental and DFT Studies of the Conversion of Ethanol and Acetic Acid on PtSn-Based Catalysts †, J. Phys. Chem. B. 109 (2005) 2074-2085. doi:10.1021/jp049354t.

[13] M.H. Brijaldo, H.A. Rojas, J.J. Martínez, F.B. Passos, Effect of support on acetic acid decomposition over palladium catalysts, J. Catal. 331 (2015) 63-75. doi:10.1016/j.jcat.2015.08.019.

[14] A. Neitzel, Y. Lykhach, V. Joha, N. Tsud, K.C. Prince, J. Libuda, Decomposition of Acetic Acid on Model Pt / CeO 2 Catalysts: The Effect of Surface Crowding, J. Phys. Chem. C. 119 (2015) 1372113734. doi:10.1021/acs.jpcc.5b03079.

[15] S.M. Lang, T.M. Bernhardt, Decomposition of acetic acid mediated by free $\operatorname{Mn} \times 0 x+(x=3,4)$ clusters, Int. J. Mass Spectrom. 433 (2018) 7-10. doi:10.1016/j.ijms.2018.07.008.

[16] H. Yan, X. Feng, Y. Liu, C. Yang, H. Shan, Catalytic cracking of acetic acid and its ketene intermediate over HZSM-5 catalyst: A density functional theory study, Mol. Catal. 437 (2017) 11-17. doi:10.1016/j.mcat.2017.04.038.

[17] M.D. Esrafili, P. Nematollahi, R. Nurazar, A density functional theory study on adsorption and decomposition of acetic acid over silicon carbide nanotubes, Synth. Met. 215 (2016) 164-169. doi:10.1016/j.synthmet.2016.02.019.

[18] F. Sanchez, M.H. Alotaibi, D. Motta, C.E. Chan-Thaw, A. Rakotomahevitra, T. Tabanelli, A. Roldan, C. Hammond, Q. He, T. Davies, A. Villa, N. Dimitratos, Hydrogen production from formic acid decomposition in the liquid phase using Pd nanoparticles supported on CNFs with different surface properties, Sustain. Energy Fuels. 2 (2018) 2705-2716. doi:10.1039/C8SE00338F.

[19] D.S. Su, S. Perathoner, G. Centi, Nanocarbons for the Development of Advanced Catalysts, Chem. Rev. 113 (2013) 5782-5816. doi:10.1021/cr300367d. 
[20] M.F.L. De Volder, S.H. Tawfick, R.H. Baughman, A.J. Hart, Carbon Nanotubes: Present and Future Commercial Applications, Science (80-. ). 339 (2013) 535-539. doi:10.1126/science.1222453.

[21] J.M. Planeix, N. Coustel, B. Coq, V. Brotons, P.S. Kumbhar, R. Dutartre, P. Geneste, P. Bernier, P.M. Ajayan, Application of Carbon Nanotubes as Supports in Heterogeneous Catalysis, J. Am. Chem. Soc. 116 (1994) 7935-7936. doi:10.1021/ja00096a076.

[22] F.R. García-García, J. Álvarez-Rodríguez, I. Rodríguez-Ramos, A. Guerrero-Ruiz, The use of carbon nanotubes with and without nitrogen doping as support for ruthenium catalysts in the ammonia decomposition reaction, Carbon N. Y. 48 (2010) 267-276. doi:10.1016/j.carbon.2009.09.015.

[23] H. Miao, S. Li, Z. Wang, S. Sun, M. Kuang, Z. Liu, J. Yuan, Enhancing the pyridinic N content of Nitrogen-doped graphene and improving its catalytic activity for oxygen reduction reaction, Int. J. Hydrogen Energy. 42 (2017) 28298-28308. doi:10.1016/j.ijhydene.2017.09.138.

[24] H. Wang, T. Maiyalagan, X. Wang, Review on Recent Progress in Nitrogen-Doped Graphene: Synthesis, Characterization, and Its Potential Applications, ACS Catal. 2 (2012) 781-794. doi:10.1021/cs200652y.

[25] X. Liu, W. Jia, G. Xu, Y. Zhang, Y. Fu, Selective Hydrodeoxygenation of Lignin-Derived Phenols to Cyclohexanols over Co-Based Catalysts, ACS Sustain. Chem. Eng. 5 (2017) 8594-8601. doi:10.1021/acssuschemeng.7b01047.

[26] S. Van Dommele, Nitrogen Doped Carbon Nanotubes: Synthesis, Characterization and Catalysis, Utrecht University, 2008.

[27] W. Xia, Interactions between metal species and nitrogen-functionalized carbon nanotubes, Catal. Sci. Technol. 6 (2016) 630-644. doi:10.1039/C5CY01694K.

[28] B. Rahzani, M. Saidi, H.R. Rahimpour, B.C. Gates, M.R. Rahimpour, Experimental investigation of upgrading of lignin-derived bio-oil component anisole catalyzed by carbon nanotube-supported molybdenum, RSC Adv. 7 (2017) 10545-10556. doi:10.1039/C6RA26121C.

[29] C. Zhou, W. Deng, X. Wan, Q. Zhang, Y. Yang, Y. Wang, Functionalized Carbon Nanotubes for Biomass Conversion: The Base-Free Aerobic Oxidation of 5-Hydroxymethylfurfural to 2,5Furandicarboxylic Acid over Platinum Supported on a Carbon Nanotube Catalyst, ChemCatChem. 7 (2015) 2853-2863. doi:10.1002/cctc.201500352.

[30] Y. Liu, Z. Chen, X. Wang, Y. Liang, X. Yang, Z. Wang, Highly Selective and Efficient Rearrangement of Biomass-Derived Furfural to Cyclopentanone over Interface-Active Ru/Carbon Nanotubes Catalyst in Water, ACS Sustain. Chem. Eng. 5 (2017) 744-751. doi:10.1021/acssuschemeng.6b02080.

[31] T.-Y. Ding, Z.-G. Zhao, M.-F. Ran, Y.-Y. Yang, Superior activity of Pd nanoparticles confined in carbon nanotubes for hydrogen production from formic acid decomposition at ambient temperature, J. Colloid 
Interface Sci. 538 (2019) 474-480. doi:10.1016/j.jcis.2018.12.017.

[32] M.R. Nabid, Y. Bide, B. Etemadi, Ag@Pd nanoparticles immobilized on a nitrogen-doped graphene carbon nanotube aerogel as a superb catalyst for the dehydrogenation of formic acid, New J. Chem. 41 (2017) 10773-10779. doi:10.1039/C7NJ01108C.

[33] Q.Y. Bi, J.D. Lin, Y.M. Liu, H.Y. He, F.Q. Huang, Y. Cao, Dehydrogenation of Formic Acid at Room Temperature: Boosting Palladium Nanoparticle Efficiency by Coupling with Pyridinic-Nitrogen-Doped Carbon, Angew. Chemie - Int. Ed. 55 (2016) 11849-11853. doi:10.1002/anie.201605961.

[34] P. Hirunsit, T. Toyao, S.M.A.H. Siddiki, K. Shimizu, M. Ehara, Origin of Nb 205 Lewis Acid Catalysis for Activation of Carboxylic Acids in the Presence of a Hard Base, ChemPhysChem. 19 (2018) 28482857. doi:10.1002/cphc.201800723.

[35] X. Ning, H. Yu, F. Peng, H. Wang, Pt nanoparticles interacting with graphitic nitrogen of N-doped carbon nanotubes: Effect of electronic properties on activity for aerobic oxidation of glycerol and electrooxidation of CO, J. Catal. 325 (2015) 136-144. doi:10.1016/j.jcat.2015.02.010.

[36] X. Ning, Y. Li, B. Dong, H. Wang, H. Yu, F. Peng, Y. Yang, Electron transfer dependent catalysis of Pt on N-doped carbon nanotubes: Effects of synthesis method on metal-support interaction, J. Catal. 348 (2017) 100-109. doi:10.1016/j.jcat.2017.02.011.

[37] Y.X. Li, M. Bowker, Acetic Acid on Rh(110): The Stabilization and Autocatalytic Decomposition of Acetate, J. Catal. 142 (1993) 630-640. doi:10.1006/jcat.1993.1236.

[38] X. Li, L. Xue, Y. Zhu, G. Chen, G. Yang, S. Wang, Mechanistic study of bio-oil catalytic steam reforming for hydrogen production: Acetic acid decomposition, Int. J. Hydrogen Energy. 43 (2018) 13212-13224. doi:10.1016/j.ijhydene.2018.05.066.

[39] A.M. Verma, N. Kishore, Decomposition of acetic acid over Ru and Ru/MgO catalyst clusters under DFT framework, Chem. Phys. Lett. 711 (2018) 156-165. doi:10.1016/j.cplett.2018.09.030.

[40] B. Pekmezci Karaman, N. Cakiryilmaz, H. Arbag, N. Oktar, G. Dogu, T. Dogu, Performance comparison of mesoporous alumina supported Cu \&amp; Ni based catalysts in acetic acid reforming, Int. J. Hydrogen Energy. 42 (2017) 26257-26269. doi:10.1016/j.ijhydene.2017.08.155.

[41] X. Li, Y. Zhu, G. Chen, G. Yang, Z. Wu, B. Sunden, Theoretical study of solvent effects on the decomposition of formic acid over a Co(111) surface, Int. J. Hydrogen Energy. 42 (2017) 24726-24736. doi:10.1016/j.ijhydene.2017.08.022.

[42] X. Li, K. Xuan, Y. Zhu, G. Chen, G. Yang, A mechanistic study on the decomposition of a model biooil compound for hydrogen production over a stepped Ni surface: Formic acid, Appl. Surf. Sci. 452 (2018) 87-95. doi:10.1016/j.apsusc.2018.05.049. 
[43] F. Sanchez, D. Motta, A. Roldan, C. Hammond, A. Villa, N. Dimitratos, Hydrogen Generation from Additive-Free Formic Acid Decomposition Under Mild Conditions by Pd/C: Experimental and DFT Studies, Top. Catal. 61 (2018) 254-266. doi:10.1007/s11244-018-0894-5.

[44] B. Delley, An all-electron numerical method for solving the local density functional for polyatomic molecules, J. Chem. Phys. 92 (1990) 508-517. doi:10.1063/1.458452.

[45] M.D. Segall, P.J.D. Lindan, M.J. Probert, C.J. Pickard, P.J. Hasnip, S.J. Clark, M.C. Payne, Firstprinciples simulation: ideas, illustrations and the CASTEP code, J. Phys. Condens. Matter. 14 (2002) 2717-2744. doi:10.1088/0953-8984/14/11/301.

[46] J.P. Perdew, K. Burke, M. Ernzerhof, Generalized Gradient Approximation Made Simple, Phys. Rev. Lett. 77 (1996) 3865-3868. doi:10.1103/PhysRevLett.77.3865.

[47] S. Grimme, Semiempirical GGA-type density functional constructed with a long-range dispersion correction, J. Comput. Chem. 27 (2006) 1787-1799. doi:10.1002/jcc.20495.

[48] K. Lejaeghere, V. Van Speybroeck, G. Van Oost, S. Cottenier, Error Estimates for Solid-State DensityFunctional Theory Predictions: An Overview by Means of the Ground-State Elemental Crystals, Crit. Rev. Solid State Mater. Sci. 39 (2014) 1-24. doi:10.1080/10408436.2013.772503.

[49] C.J. Pickard, B. Winkler, R.K. Chen, M.C. Payne, M.H. Lee, J.S. Lin, J.A. White, V. Milman, D. Vanderbilt, Structural Properties of Lanthanide and Actinide Compounds within the Plane Wave Pseudopotential Approach, Phys. Rev. Lett. 85 (2000) 5122-5125. doi:10.1103/PhysRevLett.85.5122.

[50] Y. Liu, L. Huang, D. Wei, Y. Wang, H. Zhang, G. Yu, Synthesis of N-Doped Graphene by Chemical Vapor Deposition and Its Electrical Properties, Nano Lett. 9 (2009) 1752-1758. doi:10.1021/nl803279t.

[51] S. Wang, C. Han, J. Wang, J. Deng, M. Zhu, J. Yao, H. Li, Y. Wang, Controlled Synthesis of Ordered Mesoporous Carbohydrate-Derived Carbons with Flower-like Structure and N-Doping by SelfTransformation, Chem. Mater. 26 (2014) 6872-6877. doi:10.1021/cm503669v.

[52] Y. Cao, S. Mao, M. Li, Y. Chen, Y. Wang, Metal/Porous Carbon Composites for Heterogeneous Catalysis: Old Catalysts with Improved Performance Promoted by N-Doping, ACS Catal. 7 (2017) 80908112. doi:10.1021/acscatal.7b02335.

[53] M. Zhao, Y. Xia, J.P. Lewis, R. Zhang, First-principles calculations for nitrogen-containing singlewalled carbon nanotubes, J. Appl. Phys. 94 (2003) 2398-2402. doi:10.1063/1.1593798.

[54] T. Schiros, D. Nordlund, L. Pálová, D. Prezzi, L. Zhao, K.S. Kim, U. Wurstbauer, C. Gutiérrez, D. Delongchamp, C. Jaye, D. Fischer, H. Ogasawara, L.G.M. Pettersson, D.R. Reichman, P. Kim, M.S. Hybertsen, A.N. Pasupathy, Connecting Dopant Bond Type with Electronic Structure in N-Doped Graphene, Nano Lett. 12 (2012) 4025-4031. doi:10.1021/nl301409h. 
[55] M. Terrones, A. Jorio, M. Endo, A.M. Rao, Y.A. Kim, T. Hayashi, H. Terrones, J.-C. Charlier, G. Dresselhaus, M.S. Dresselhaus, New direction in nanotube science, Mater. Today. 7 (2004) 30-45. doi:10.1016/S1369-7021(04)00447-X.

[56] W.J. Lee, U.N. Maiti, J.M. Lee, J. Lim, T.H. Han, S.O. Kim, Nitrogen-doped carbon nanotubes and graphene composite structures for energy and catalytic applications, Chem. Commun. 50 (2014) 6818. doi:10.1039/c4cc00146j.

[57] Q. Wei, X. Tong, G. Zhang, J. Qiao, Q. Gong, S. Sun, Nitrogen-Doped Carbon Nanotube and Graphene Materials for Oxygen Reduction Reactions, Catalysts. 5 (2015) 1574-1602. doi:10.3390/catal5031574.

[58] X. Ning, Y. Li, J. Ming, Q. Wang, H. Wang, Y. Cao, F. Peng, Y. Yang, H. Yu, Electronic synergism of pyridinic- and graphitic-nitrogen on N-doped carbons for the oxygen reduction reaction, Chem. Sci. 10 (2019) 1589-1596. doi:10.1039/C8SC04596H.

\section{Figures}

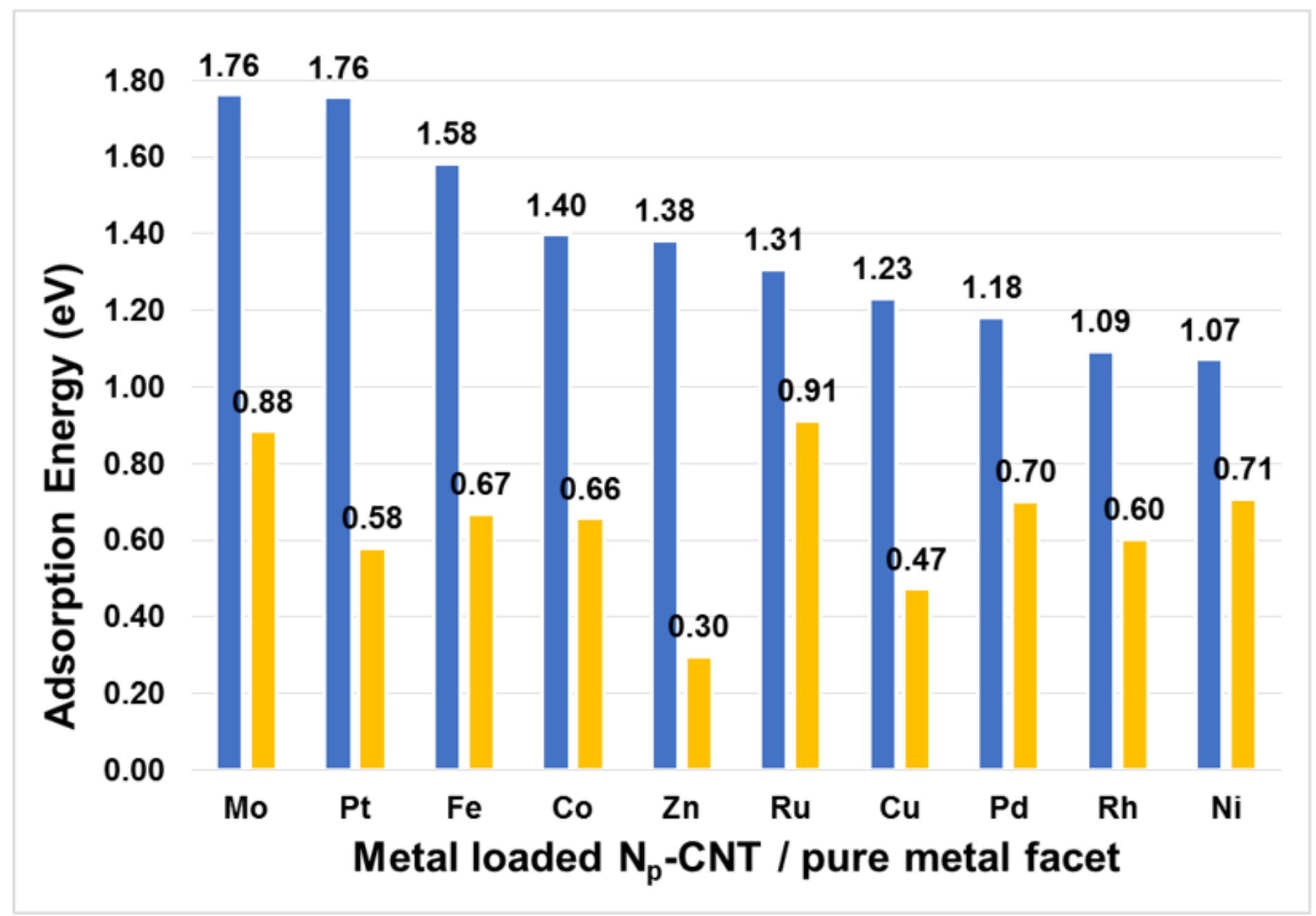

Figure 1 
Adsorption energy of AcOH over metal loaded Np-CNTs (blue bars) and over pure metal facets (yellow bars).
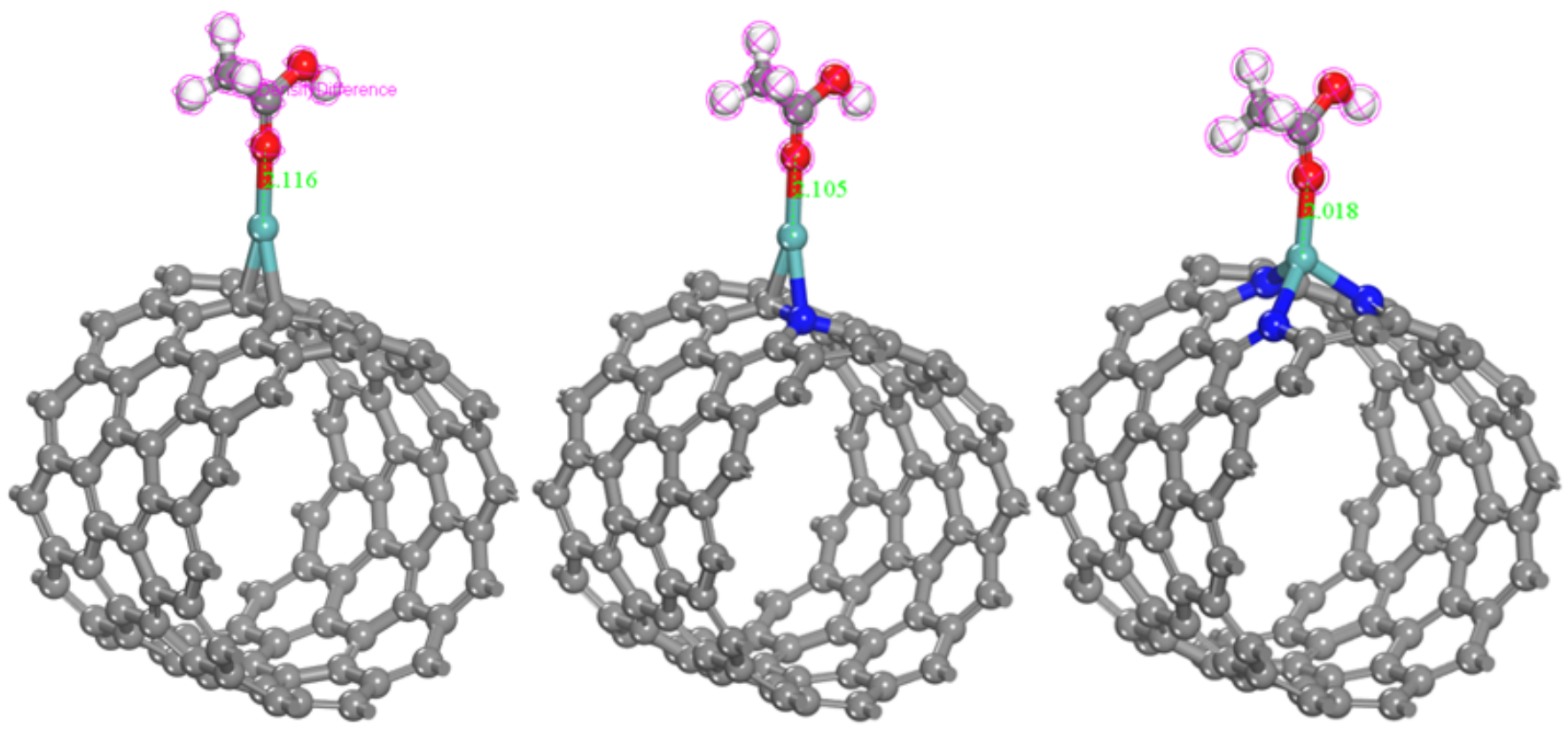

Figure 2

Models of (a) Mo/CNT (b) Mo/Ng-CNT (c) Mo/Np-CNT (grey denotes carbon, green denotes Mo, blue denotes nitrogen, red denotes oxygen and white denotes hydrogen)

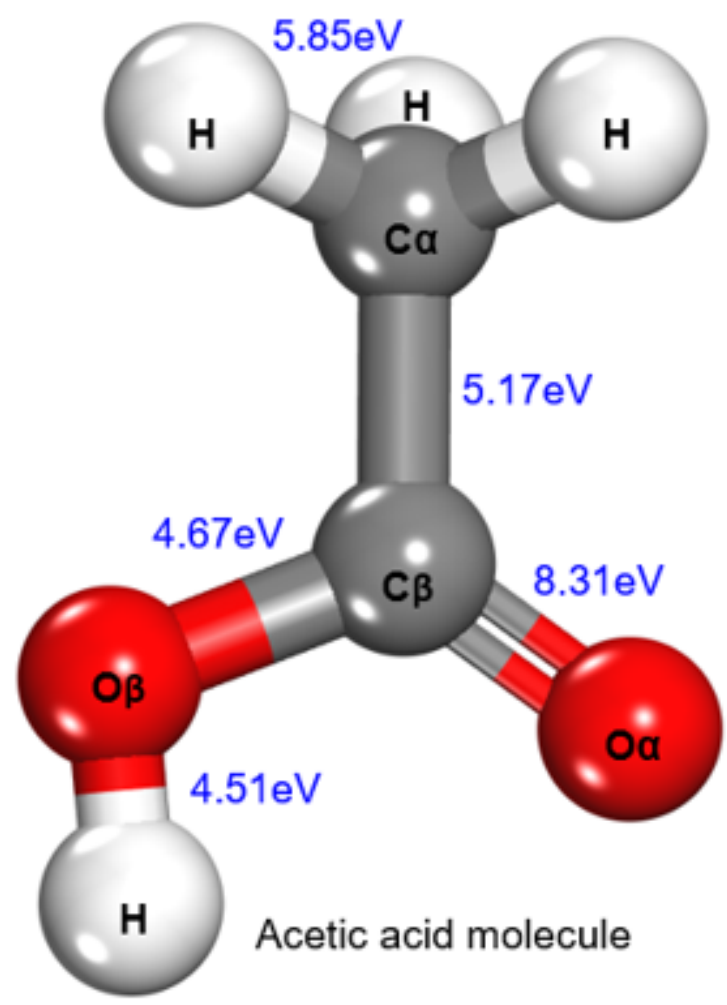


Figure 3

$\mathrm{AcOH}$ molecule and the bond dissociation energy of each bond (blue font) in the free molecule [5]

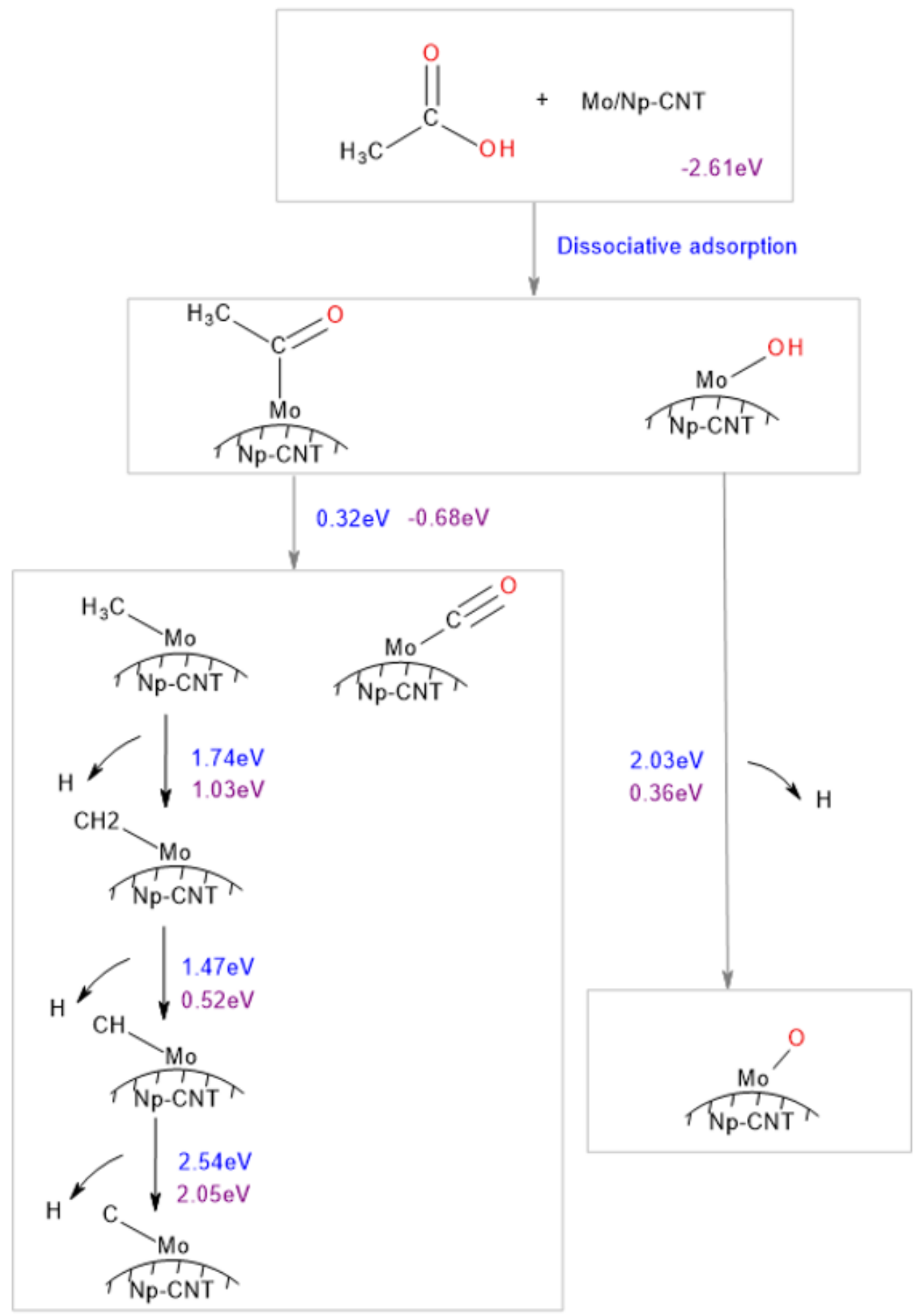

\section{Figure 4}

Reaction flow of the decomposition of $\mathrm{AcOH}$ over Mo/Np-CNT (Blue font denotes energy barrier, and violet denotes reaction energy) 


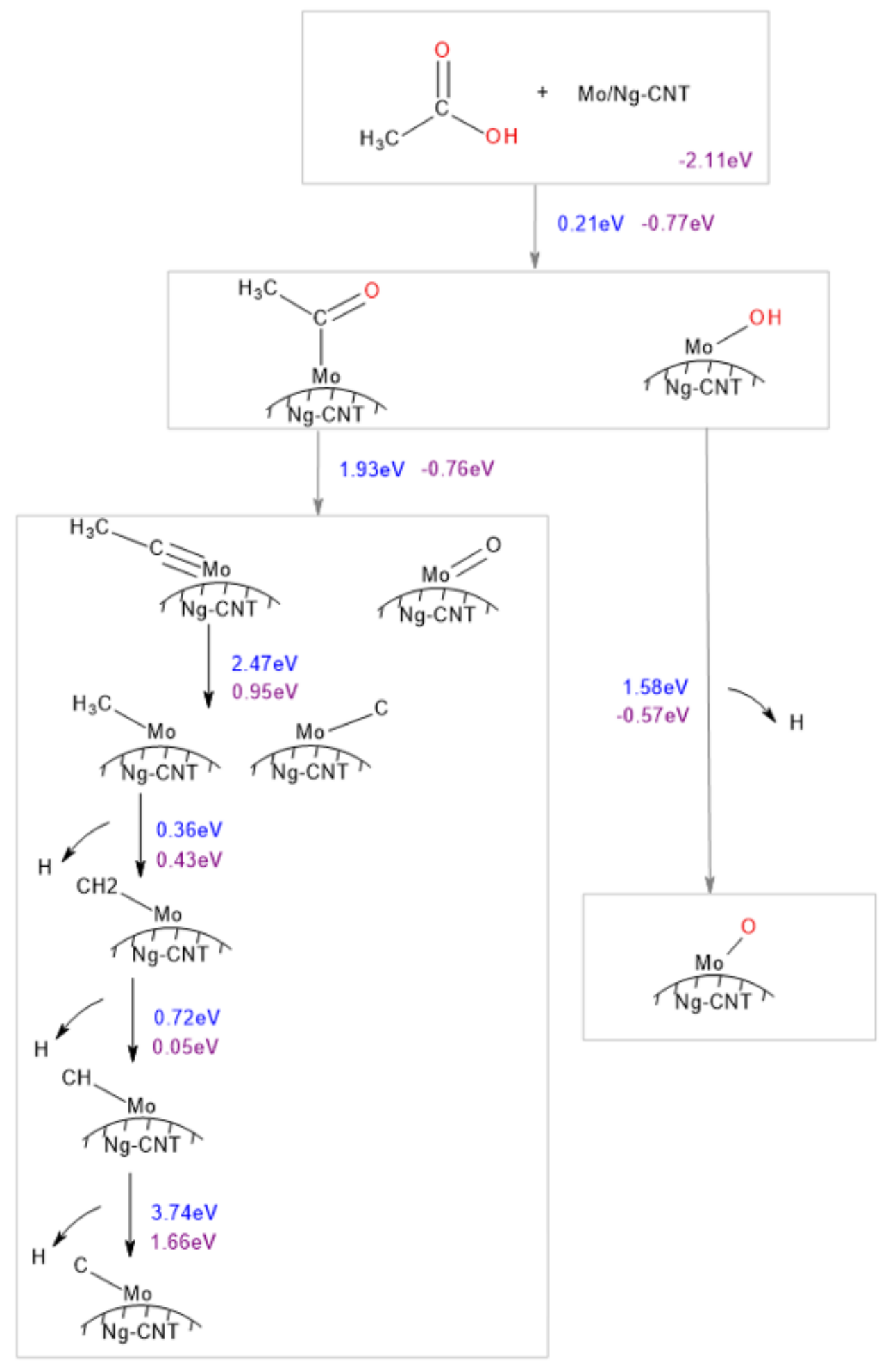

Figure 5

Reaction flow of the decomposition of $\mathrm{AcOH}$ over $\mathrm{Mo} / \mathrm{Ng}-\mathrm{CNT}$ (Blue font denotes energy barrier, and violet denotes reaction energy) 


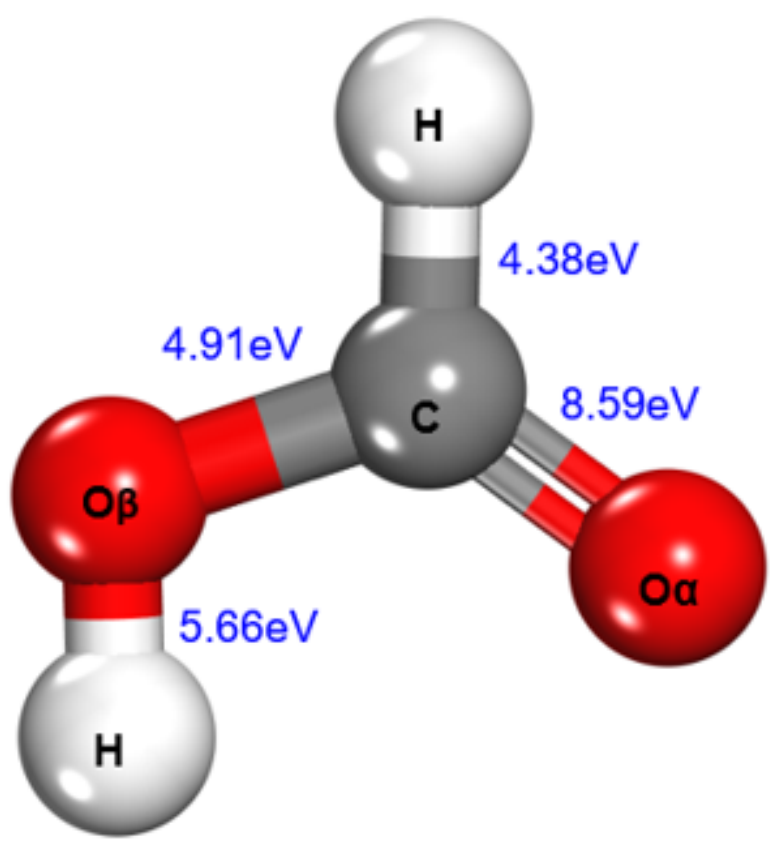

Formic acid molecule

Figure 6

FA molecule with cleavage energy barriers (blue font) in free molecule [5] 


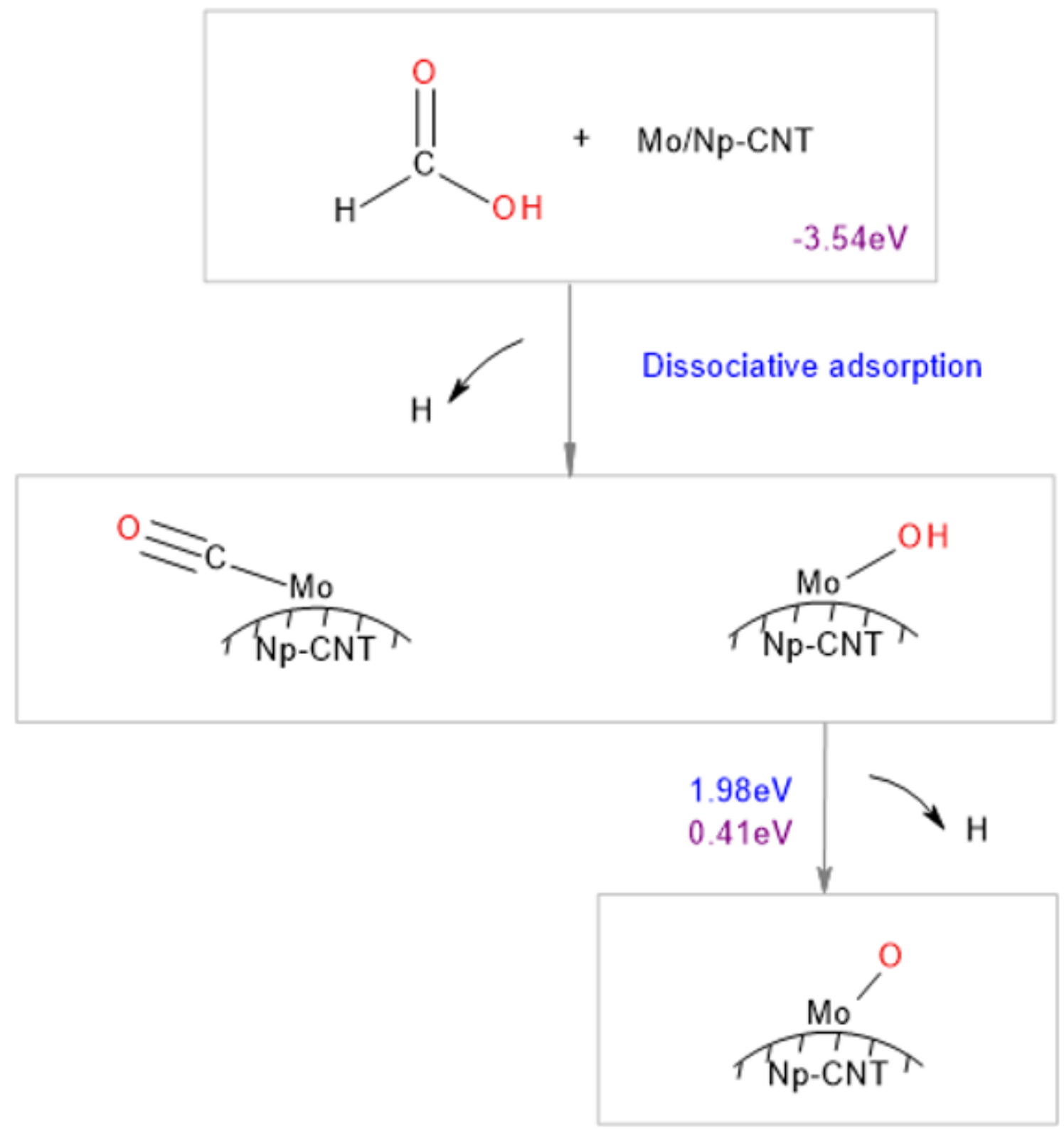

Figure 7

Reaction flow of the decomposition of FA over Mo/Np-CNT (Blue font denotes energy barrier, and violet denotes reaction energy) 


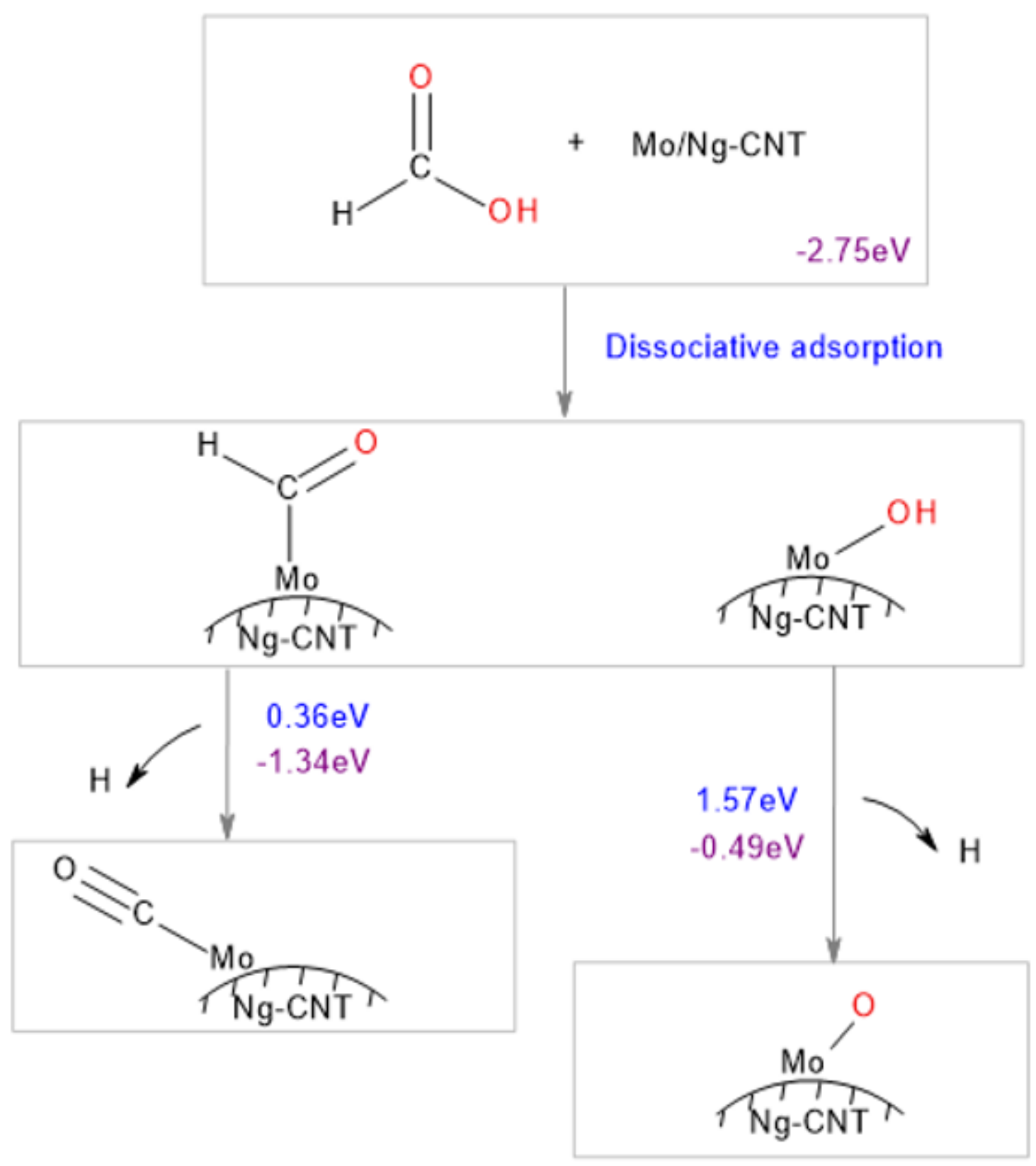

Figure 8

Flow chart for the decomposition reaction of FA over Mo/Ng-CNT (Blue font denotes energy barrier, and violet denotes reaction energy) 


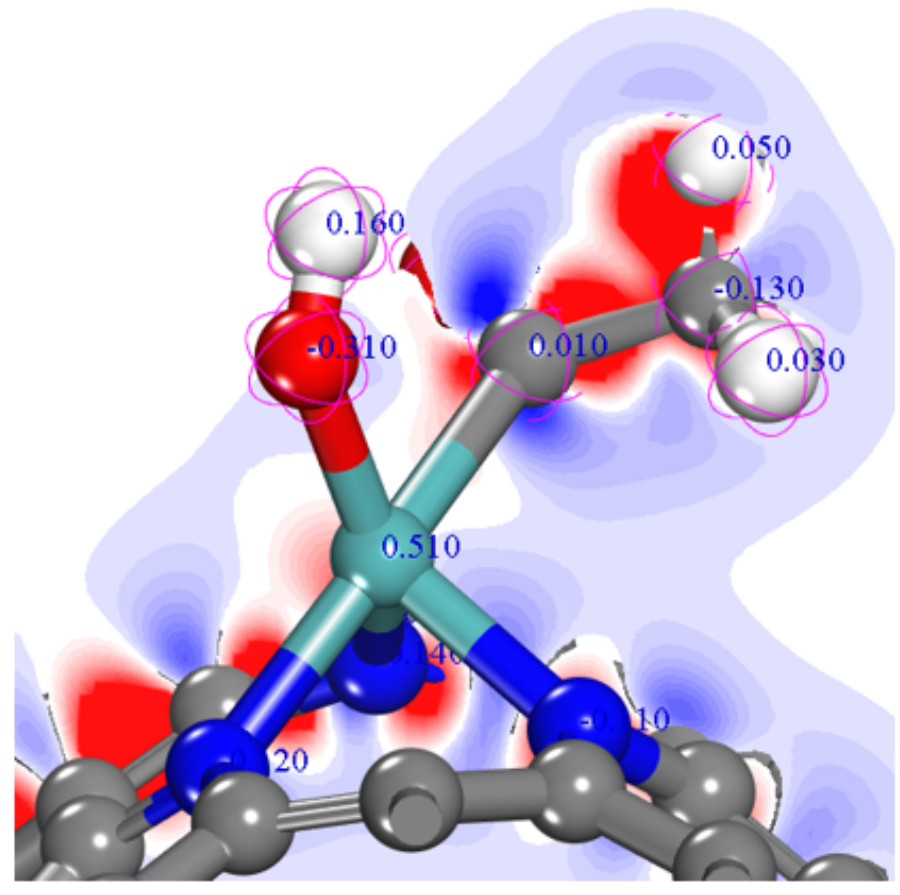

(a)

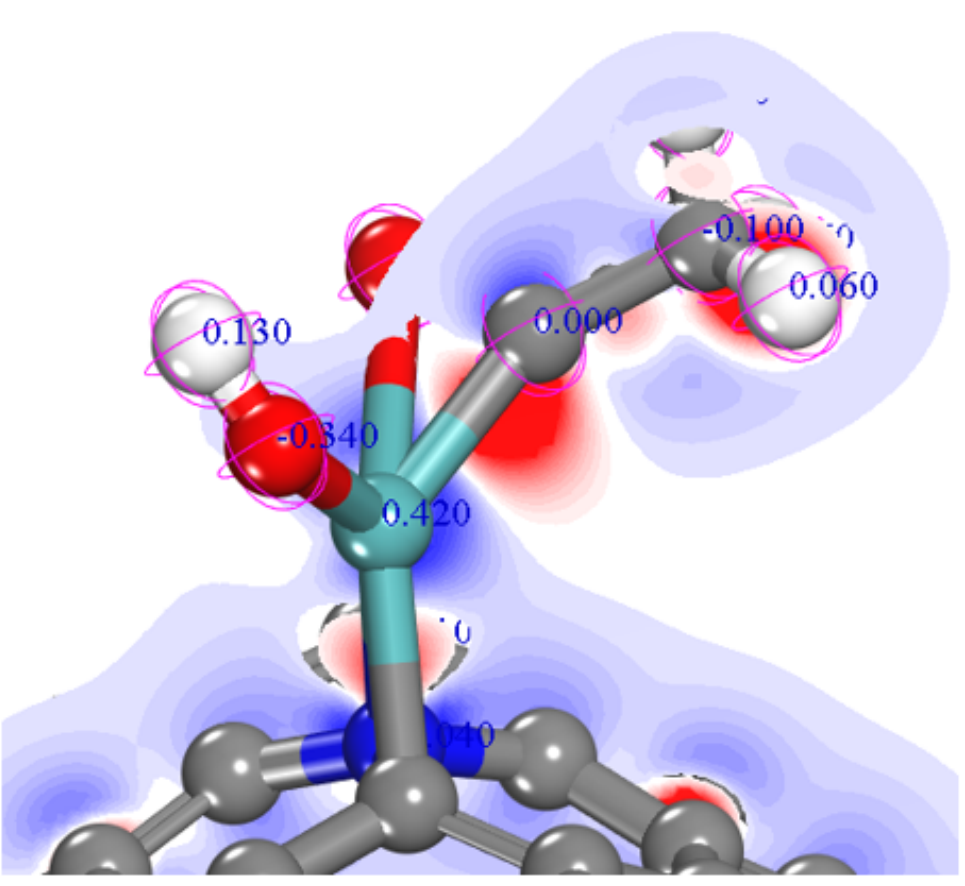

(b)

Figure 9

EDD analyses (threshold value: +/- 0.2 electrons/Å3) of the $\mathrm{C}-\mathrm{C}$ bond structures with atomic charges on (a) Mo/Np-CNT (b) Mo/Ng-CNT. Red denotes electron enrichment and blue denotes electron loss 


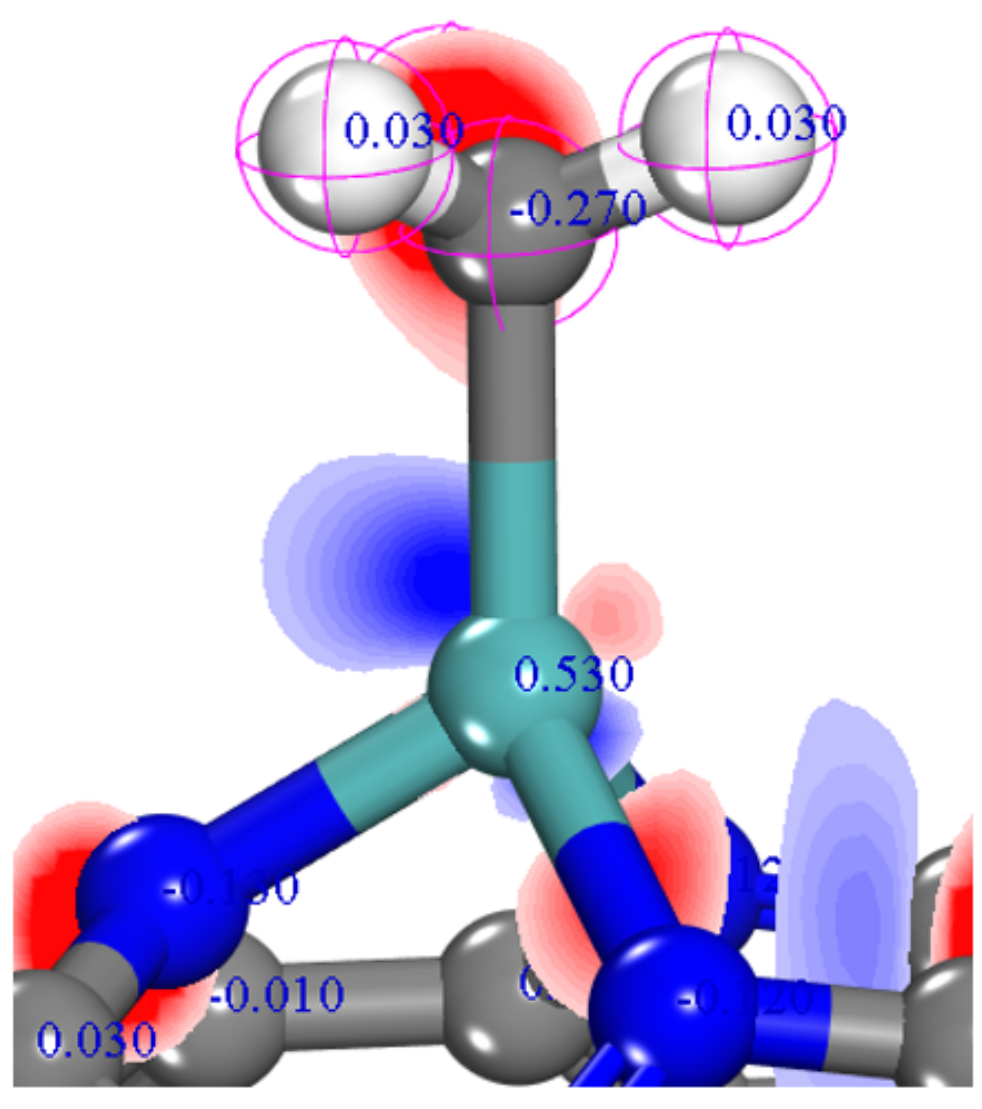

(a)

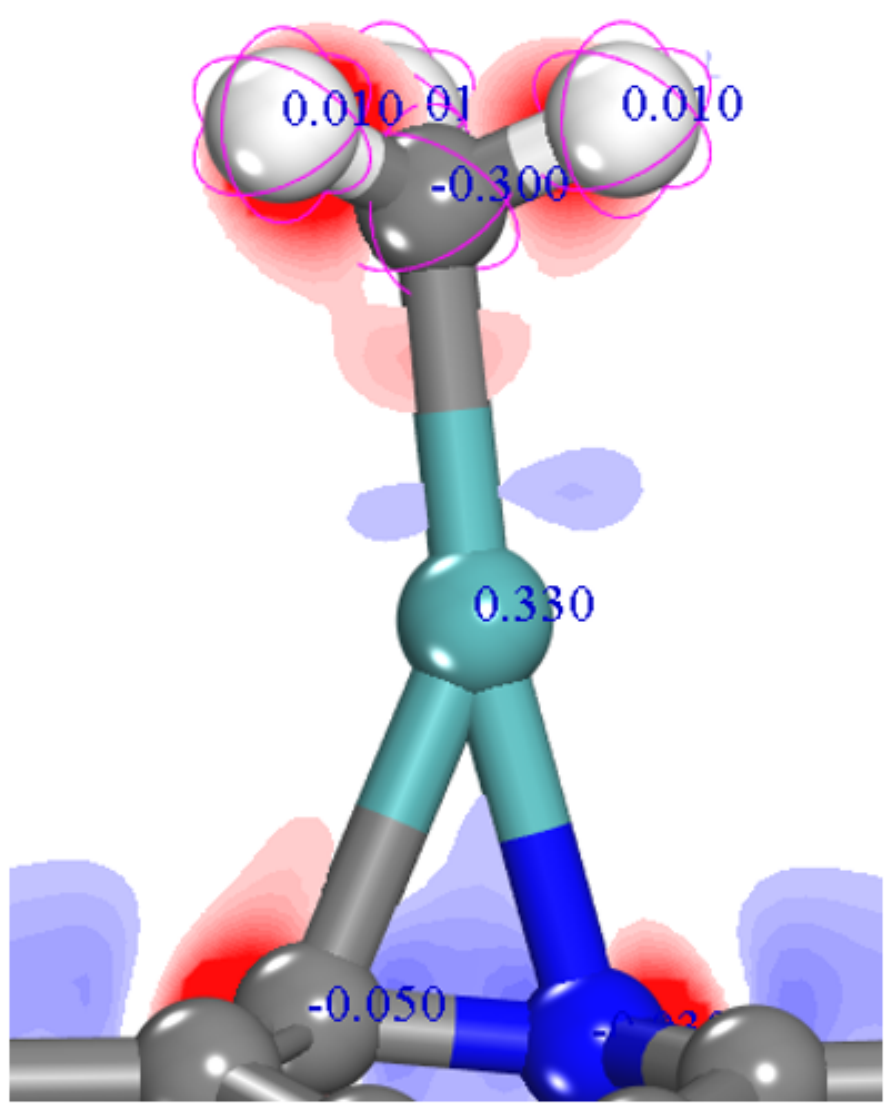

(b)

\section{Figure 10}

EDD analyses (threshold value: +/- 0.2 electrons/Å3) of the methyl groups with atomic charges on (a) $\mathrm{Mo} / \mathrm{Np}-\mathrm{CNT}$ (b) Mo/Ng-CNT. Red denotes electron enrichment and blue denotes electron loss 


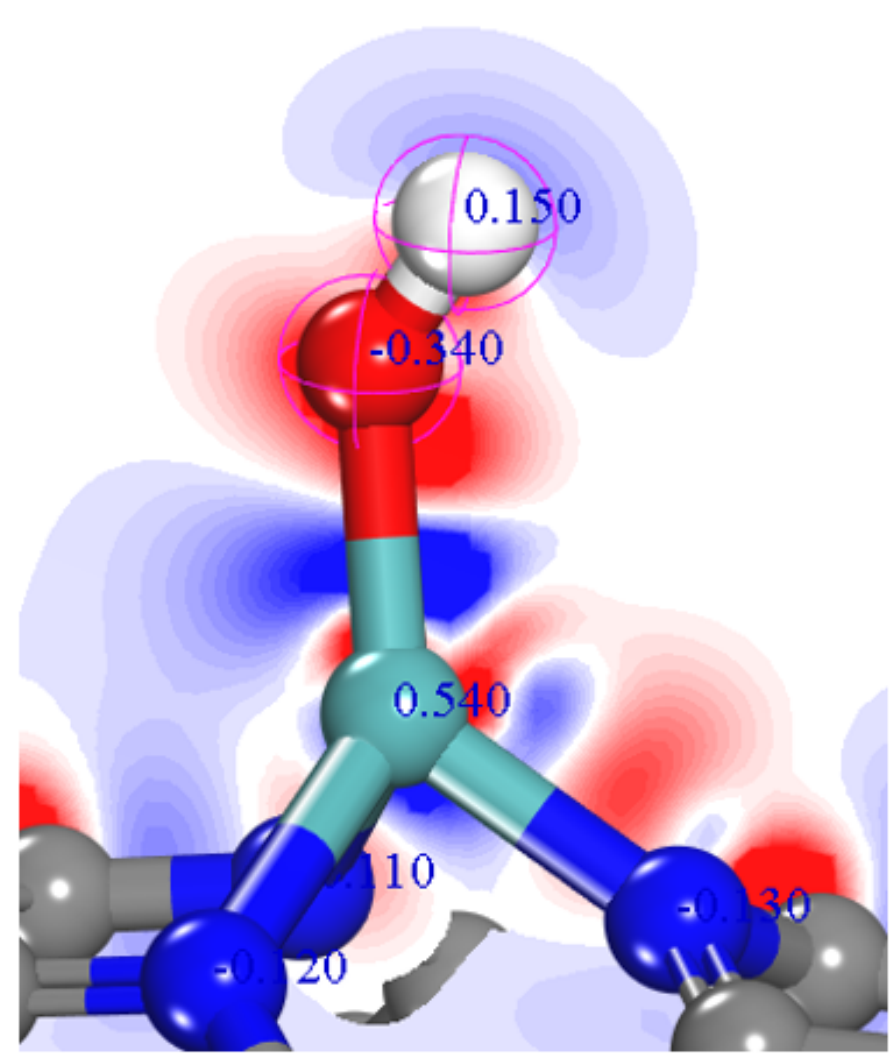

(a)

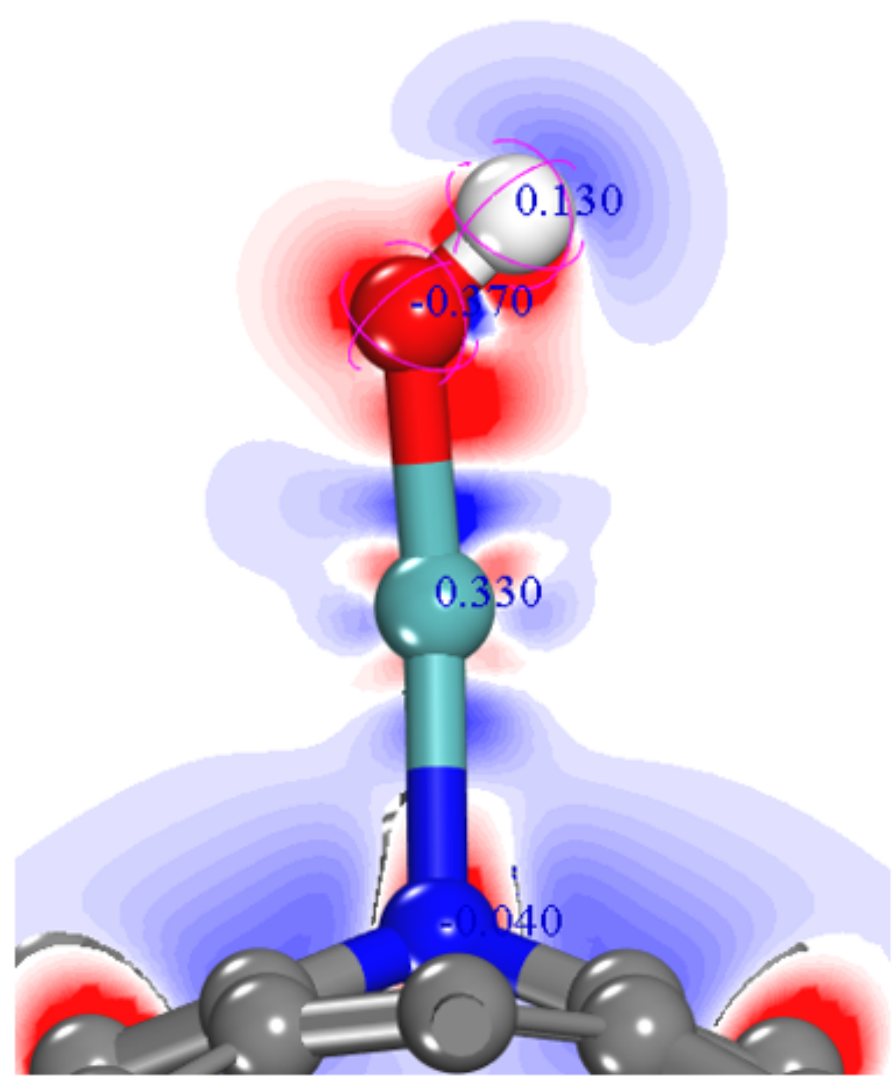

(b)

\section{Figure 11}

EDD analyses (threshold value: +/- 0.2 electrons/Å3) of the hydroxyl groups with atomic charges on (a) $\mathrm{Mo} / \mathrm{Np}-\mathrm{CNT}$ (b) Mo/Ng-CNT. Red denotes electron enrichment and blue denotes electron loss 


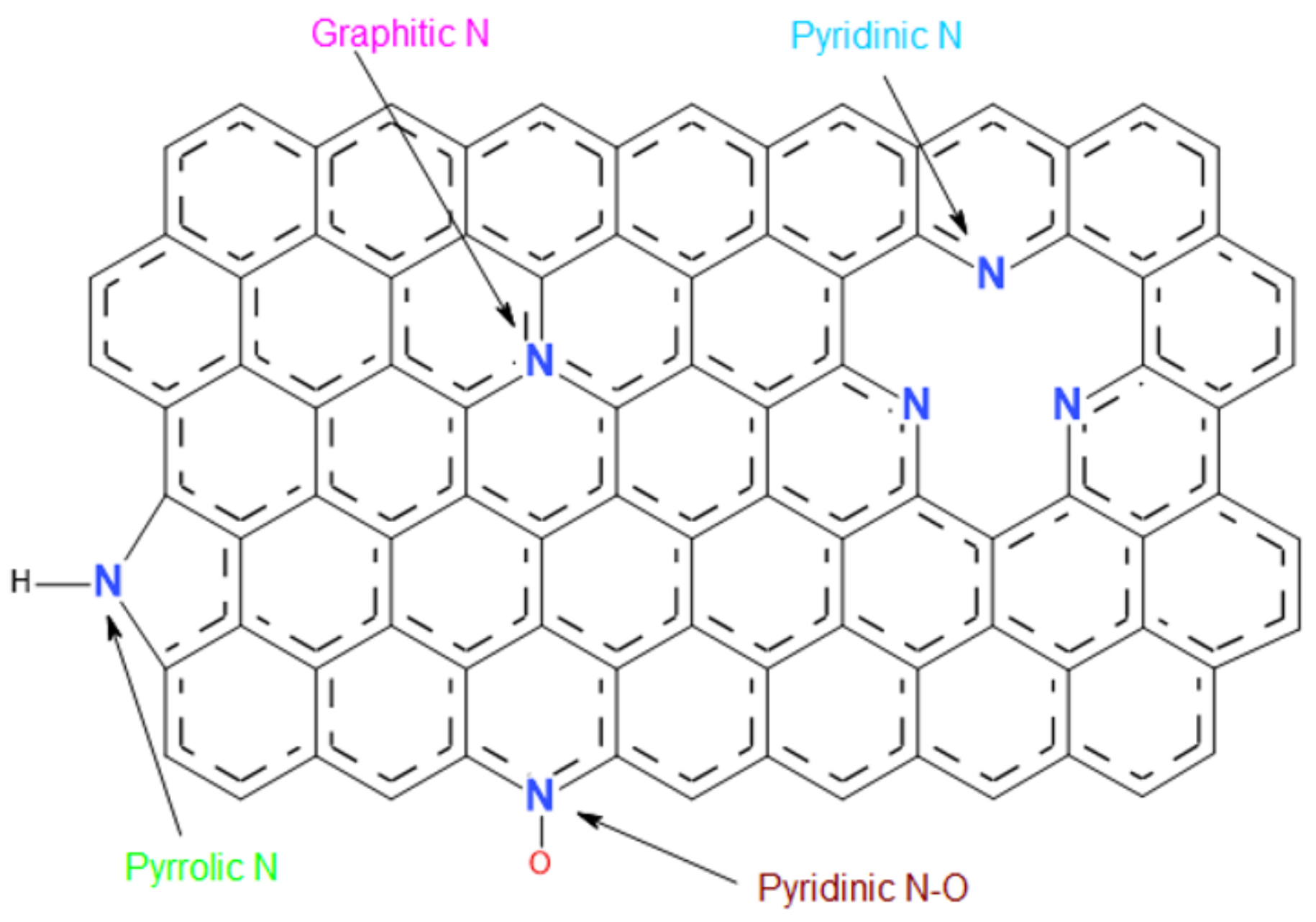

Figure 12

Common types of $\mathrm{N}$ doping in carbon matrices $[51,56]$

\section{Supplementary Files}

This is a list of supplementary files associated with this preprint. Click to download.

- SupplementaryMaterialv4submit.docx 